تحفيز التغايرات الوراثية باستخدام مستخلص ثمار الحنظل واستحثاث الكالس لأجنة بذور تركيبين وراثيين من

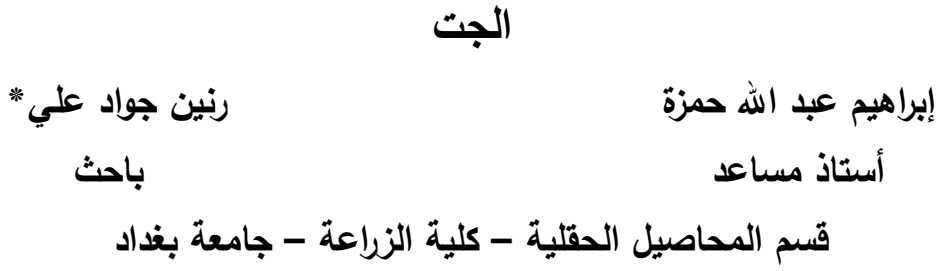

qweenrose98@gmail.com

المستخلص

نفذت تجربة في المختبر المركزي لزراعة الانسجة النباتية - الدراسات العليا - كلية الزراعة - جامعة بغداد للمدة من تموز 2015 إلى

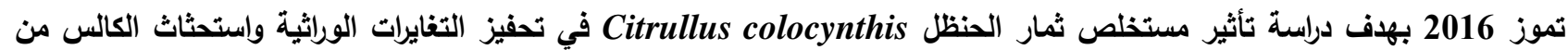
أجنة تركيبين وراثيين (PAC-78001 والمحي) من الجت باستعمال تقانة زراعة الأنسجة بتصميم التجارب العاملية على وفق ترتيب

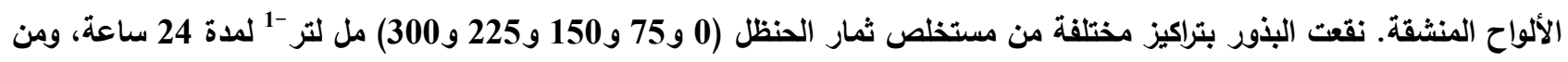
ثم عقمت البذور بتركيز 4.5\% من محلول هايبوكلورات الصوديوم NaOCl لمدة 15 دقيقة. اظهرت النتائج وجود اختلاف معنوي بين التركيبين الوراثيين للجت في استجابتهما لمستويات مختلفة من مستخلص ثمار الحنظل، إذ اعطى التركيز 150 مل لتر-1' أعلى معدل

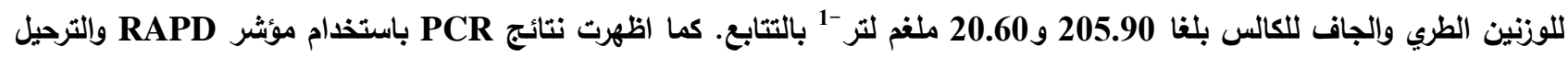
على هلام الأكروز لعينات DNA المعزولة من كالس التركيبين الوراثيين للجت والمعرضين لتراكيز مختلفة من مستخلص ثمار الحنظل

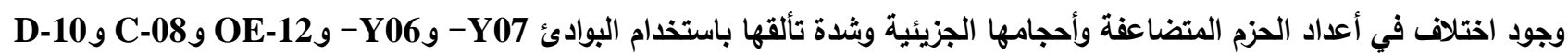
A- A-16-Y10، ولم يظهز أي اختلاف في عدد الحزم ولتراكيز مستخلص ثمار الحنظل جميعها في التركيب الوراثي المحلي للبادئ

الكلمات المفتاحية: الجت، زراعة الأنسجة النباتية، استحثاث الكالس، مؤثر RAPD.

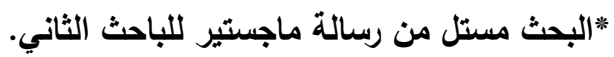

The Iraqi Journal of Agricultural Sciences -749-764: (3) 48/ 2017

Hamza \& Ali

\title{
PRIMING OF GENETIC VARIATIONS BY COLOCYNTH FRUIT EXTRACT AND CALLUS INITIATION IN EMBRYOS OF TWO CULTIVARS OF ALFALFA SEEDS
}
I. A. Hamza
R. J. Ali*
Assist. Prof.
Researcher

Dept. of Field Crops - Coll. of Agric. Univ. of Baghdad

\section{ABSTRACT}

qweenrose98@gmail.com

An experiment was conducted at Central lab of Graduate studies, College of Agriculture, University of Baghdad during 2015-2016. The aim was to study the effect of colocynth fruit extract on inducing callus from embryos of two alfalfa cultivars were PAC-78001 and local variety by tissue culture technique using factorial experiment within CRD. Seeds was soaked with colocynth fruit extract at $0,75,150,225$, and $300 \mathrm{ml} \mathrm{Li}^{-1}$ for 24 hours, then, sterilized by $\mathrm{NaOCl}$ at $4.5 \%$ for 15 minutes. The results showed significant differences between two cultivars responding to colocynth fruit extract levels. Concentration at $150 \mathrm{ml} \mathrm{Li}^{-1}$ gave the highest both fresh and dry weight of callus (205.90 and 20.60) respectively. Also, PCR results depending on RAPD and electrophoresis for DNA samples which isolated from callus of two cultivars and subjected to various concentrations of colocynth fruit extract $0,75,150,225$ and $300 \mathrm{ml} \mathrm{Li}^{-1}$ showed differences in amplified observed bands, molecular weights and brightness intensity by using primers primer -Y07, -Y06, OE-12, C-08, D-10, -Y10 and A-16, and There was no difference in bands number at all concentrations of colocynth fruit extract for local variety by primer A-16.

Key words: Alfalfa, plant tissue culture, callus induced, RAPD.

*Part of M.Sc. thesis of the second author. 
الوصف الأساسي لجزيئة DNA الذي يستعمل لمعرفة

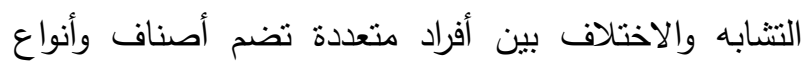
نباتية مختلفة (14)، وبالامكان تشخيص الطفرات وتقدير التباين الوراثي من خلال دراسة التنوع البايوكيميائي الذي لني يشمل التتوع في البروتينات والأنزيمات المتتاظرات الأنزيمية والتتوع في نواتج الأيض الثانوي والمسارات الأيضية فضلات

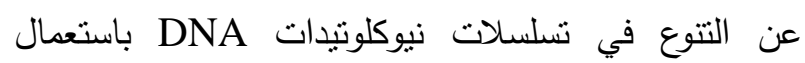

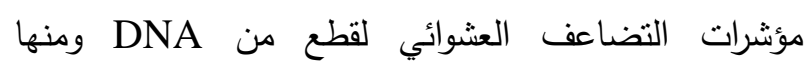
تقانة PCR لغرض معرفة البصمة الوراثية وأكثرها شيوعا هو لهن مؤشر RAPD وتحتاج هذه التقانة بشكل أساسي إلى بادئات

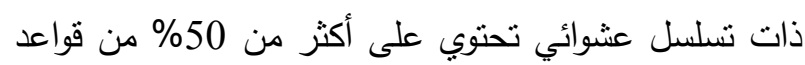

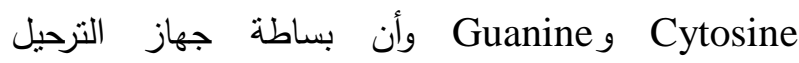
الكهربائي جعلت من هذه التقانة سهلة وسريعة (26)، وهناك

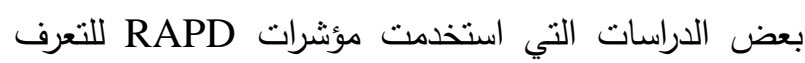

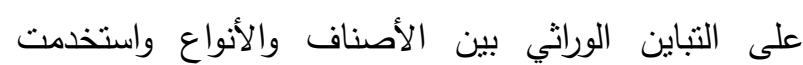
طريقة Redicago كثيرا لجنس لتقدير التغايرات الوراثية للجت لتحديد الخرائط الجينية (9). اشارت Baday (3) إلى وجود اختلاف في أعداد الحزم وأوزانها الجزيئية باستخدام مؤشر RAPD في تقدير التباين الوراثي لصنفين

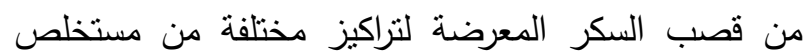
الحنظل 0 و 50 و100 و 150 و 200 مل لتر -1 باستخدام 5 بوادئ عشوائية، وهذا يعود إلى نأثثير مستخلص الحنظل وتراكيزه في الأنسجة النباتية. لذا يهدف البحث إلى إلى تحفيز

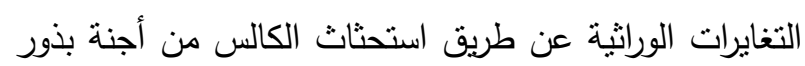
تركيبين وراثيين من الجت لإنتاج خطوط خلايا متحملة للملوحة من خلال زراعة الكالس على تراكيز مختلفة من ونين مستخلص ثمار الحنظل.

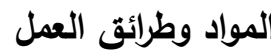

نفذت تجربة في مختبر زراعة الانسجة النباتية - الدراسات العليا - كلية الزراعة - جامعة بغداد للمدة من بداية شهر تموز 2015 حتى شهر تموز 2016 بهدف استحثناث التغايرات الوراثية خارج الجسم الحي باستخدام مستخلص لهرد ثمار الحنظل لتركيبين وراثيين من الجت. غسلت بذور التركيبين الوراثيين للجت (المحلي و PAC-78001) بماء الحنفية الجاري لمدة 5 دقائق قبل البدء بالزراعة لغرض لتراين التخلص من الثوائب والأتربة العالقة بها، بعدها نقعت بذور
المقدمة

يعد محصول الجت من محاصيل العائلة البقولية المهمة والذي يحتل المرتبة الأولى من بين المحاصيل العلفية، ويتميز بقيمته الغذائية العالية للحيوان ولاسيما الأبقار والأغنام والدواجن والأسماك، كما يتميز بإنتاجية عالية من المادة

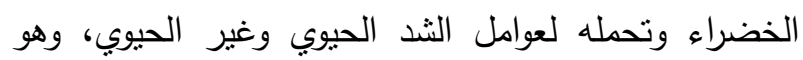

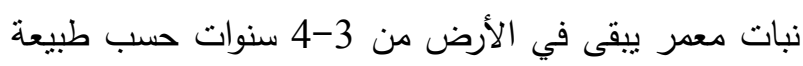
التربة وعوامل الخدمة (5) وتصل نسبة البروتين فيه 22.9 والكربوهيدرات 36.1\% والدهون 2.5\% عند وصول ولثهل النبات إلى بداية التزهير، وهذه النسب محسوبة على أساس النسبة المئوية للوزن الجاف للجت (10)، ويتميز محصول الجت بإنتاجيته العالية ومحافظته على التربة وتتبيت النتروجين الجوي من ثم التقليل من استعمال المركبات الكيميائية التي تعمل على تلوث التربة والمياه الجوفية (25). يعد الاجهاد

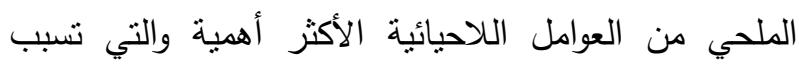

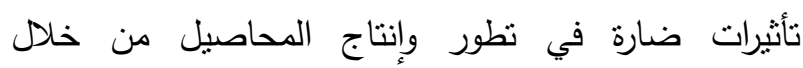
التغايرات الفسيولوجية والكيميائية والجزيئية (15 و و24)،

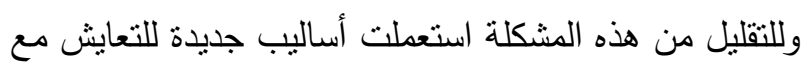
الملوحة من خلال تطوير تراكيب وراثية من المحاصيل تكون هن هندئ

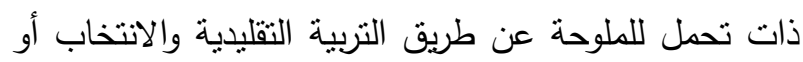

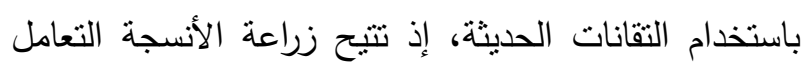
مع أعداد هائلة من الخلايا النباتية واجراء عملية الغربلة

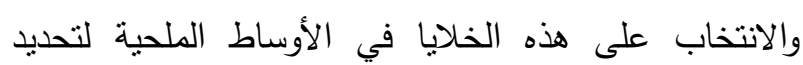

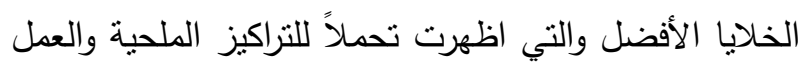
على تمايزها إلى نباتات وتجذيرها وأقلمنها ومن ثم اختبارها

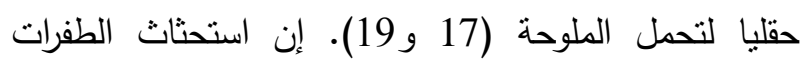
وتوظيف تقانة زراعة الانسجة للتعامل مع الخلايا المطفرة ساعد في الحصول على سلالات نقية ذات صفات مرغوبة وقد أنتتت نجاحآ كبيرآ في تحسين صفات المحاصيل المختلفة، والذي انعكس على زيادة الإنتاج والحصول على نَّلى

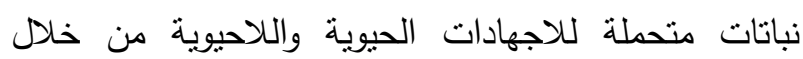
استحثاث الكالس وتطفيره وتعريضه إلى اجهادات الملوحة والجفاف والبرودة وغيرها (22)، إذ إن استخدام الصفات

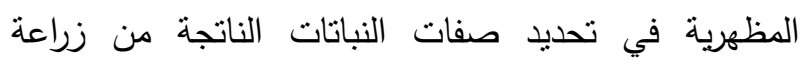
الانسجة هو محدود وغير مفيد بالمقارنة مع الصفات الوراثية،

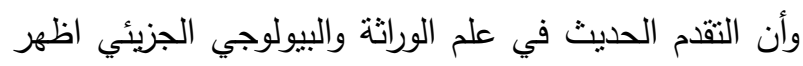


الفرن الكهربائي على درجة حرارة 70 م لددة 48 ساعة

ولحين ثبات الوزن لتحديد الوزن الجاف (1).

جدول 1. مكونات الوسط الغذائي MS لاستحثاث الكالس لون لهن

من أجنة بذور الجت

\begin{tabular}{|c|c|}
\hline التركيز ملغ لتر -1 & المادة \\
\hline 4330 & MS \\
\hline 100 & Myo-inositol \\
\hline 2 & 2,4-D \\
\hline 0.50 & Kin. \\
\hline (0 و75 و150 و225 و300) مل لتر-1 & Citrullus colocynthis \\
\hline 0.4 & Thiamine-HCl \\
\hline 2 & Glycine \\
\hline 2 & Nicotinc acid \\
\hline 0.5 & Pyrodoxine - $\mathrm{HCl}$ \\
\hline 30000 & Sucrose \\
\hline 7000 & Agar \\
\hline
\end{tabular}

استخلاص DNA

عزلت المادة الوراثية DNA من معاملات مستخلص ثمار

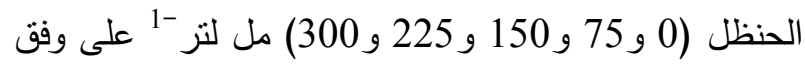

طريقة Dellaprota وآخرون (8).

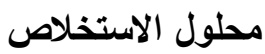

Wizard Genomic DNA Purification Kit استعمل في استخلاص DNA والمجزز من شركة Promega الأمريكية المنشأ بالكميات الآتية:

\begin{tabular}{|c|c|}
\hline الحجم لعينة واحدة ( & المادة \\
\hline 600 & Nucleilysis solution \\
\hline 3.00 & RNase solution \\
\hline 200 & Protein precipitation solution \\
\hline 100 & DNA rehydration solution \\
\hline
\end{tabular}

Polymerase Chain-PCR تفاعل البلمرة المتسلسل

Reaction

استعمل إثثا عشر بادئاً عشوائياً تم الحصول عليها من

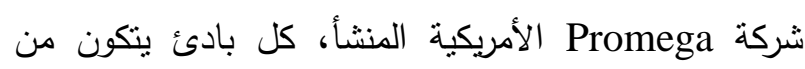
عشر نيوكليوتيدات عشوائية وتسلسلها القاعدي كما يأتي:

$\begin{array}{cc}\text { Primer } & \text { Sequence }\left(5^{\prime}-3^{\prime}\right) \\ \text { A-16 } & \text { AGCCAGCGAA } \\ \text { C-08 } & \text { TGGACCGGTG } \\ \text { D-10 } & \text { GGTCTACACC } \\ \text { OE-12 } & \text { TTATCGCCCC } \\ \text {-Y06 } & \text { AAGGCTCACC } \\ - \text { Y07 } & \text { AGAGCCGTCA } \\ - \text { Y10 } & \text { CAAACGTGGG }\end{array}$

أما البرنامج الذي استعمل لاجراء عملية تضخيم قطع DNA

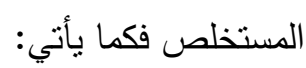

التركيبين الوراثيين للجت بتراكيز مختلفة من مستخلص ثمار

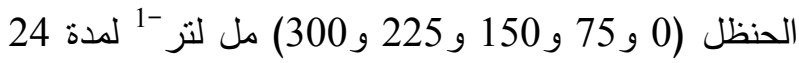

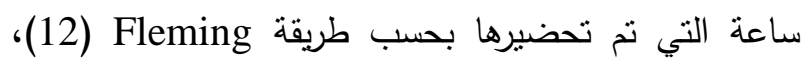
ومن ثم نقلت البذور المعاملة بالمستخلص إلى منضدة بـا الزراعة Limener ari flow cabeant) منضدة أنسياب الهواء الطبقي) لاجراء عملية التعقيم السطحي للبذور باستعمال محلول القاصر التجاري هاييوكلورات الصوديوم NaOCl

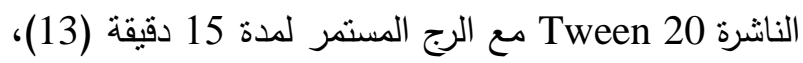
وبعدها غسلت البذور المعقمة بالماء المقطر المُعقم ثلاث مرات لازالة المنبقي من المادة المعقمة، وسُجلت نسبة التلوث

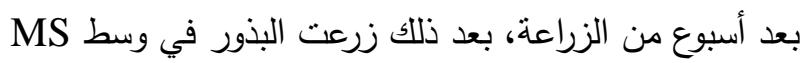

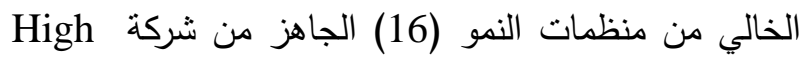
بوزن 4.33 غم لتز -1 في مراحل الزراعة جميعها والمُجهز بـ 30 غم لنز -1 سكروز ، واكمل الحجم إلى لئ 800 مل وعُل الاس الهيدروجيني pH إلى 5.70 باستعمال هيدروكسيد الصوديوم Sodium hydroxide) NaOH أو الو حامض الهيدروكلوريك Hydrochloric acid) HCl) واحد عباري واكمل الحجم إلى 1000 مل واضيف 7 غم لتر -1 من Agar بدرجة 121 جُ وضغط 1.04 كغم سم (Autoclave) ولمدة 15 دقيقة لغرض تحفيز نمو الأجنة. استثئت الأجنة النامية لبذور الجت بمجرد ملاحظة ظهور الجذير بعد 48 ساعة بأجراء عملية الضغط الخفيف على البذرة من جهة

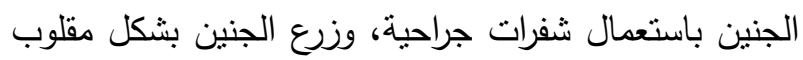

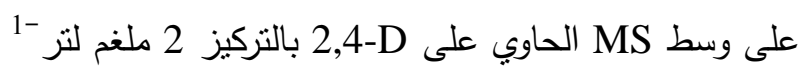
والكاينتين بالتركيز 0.5 ملغم لتر -1 لغرض استحثاث الكالس،

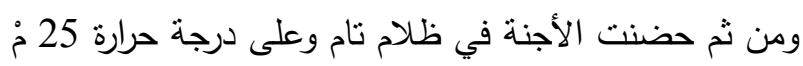
I 2 بعد أربعة أسابيع وسجل الوزن الطري والجاف للكالس

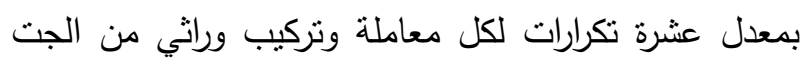

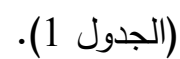
قياس الوزنين الطري والجاف استعمل الميزان الأكتروني الحساس في تحديد الوزن الطرين،

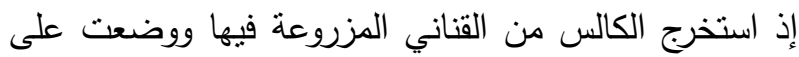
ورق الترشيح وازيلت بقايا الوسط الغذائي باستعمال شفرة جراحية وحسب الوزن الطري للكالس، وجفقت النموات في لهابـ 
الحزم عن حفر تحميلها داخل الهلام الممثلة على المحور السيني، قيست المسافة التي قطعتها كل حزمة (القطعة

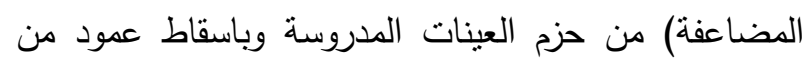
تلاك المسافة على المنحنى القياسي ومن نقطة التقاطع هذه تم اسقاط عمود آخر على المحور الصادي ليمنل حجم القطعة لهني

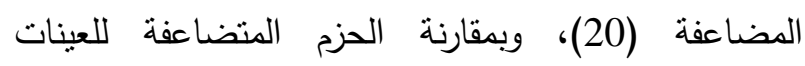
المدروسة والناتجة من تفاعل RAPD مع حزم DNA القياسي وتقدير أحجامها الجزيئية حصلنا على نواتج تفاعلات DعA J RAPD البادئ المستخدم. نفذت التجارب باستعمال التجارب العاملية في التصميم العشوائي الكامل (CRD)، وحللت النتائج

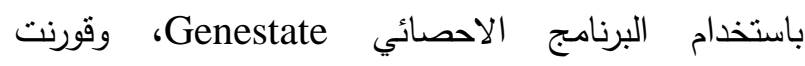
المتوسطات بحسب إختبار أقل فرق معنوي (LSD) وعلى الاحئ مستوى احتمال 5\% (11). النتائج والمناقشة المنال تأثير تراكيز مستخلص ثمار الحنظل والتراكيب الوراثية في وزن الكالس الطري في وسط MS تانير المضاف إليه 2 ملفم

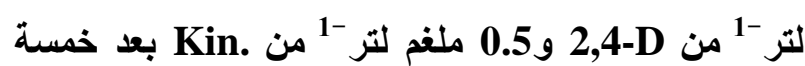
أسابيع من الزراعة من لترة يوضح الجدول 2 وجود اختلافا معنويا بين التراكيب الوراثية للجت في معدل الوزن الطري للكالس، فقد اعطى التركيب

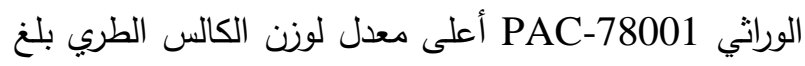
211.86 ملغم واختلف معنوياً عن التركيب الوراثي المحلي الذي اعطى 129.70 ملغم. كما يظهر من نتائج الجدول 2

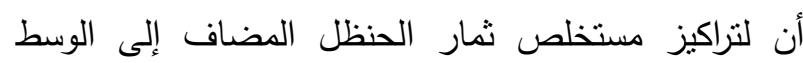

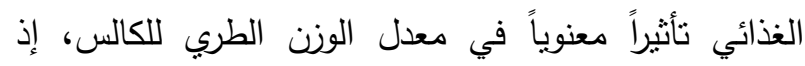
يلاحظ أن الوسط الغذائي MS المجهز بتركيز 150 مل فلئل لتز -1 من مستخلص ثمار الحنظل اعطى أعلى معدل لوزن بـن

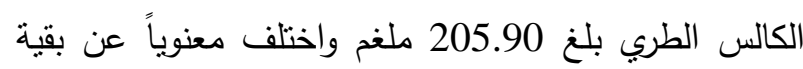
المعاملات التي كان أقلها في الوسط الغذائي MS المجزي

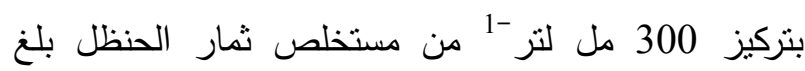

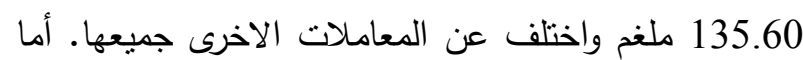
عن التداخل بين العاملين فيبين الجدول 2 وجود تداخل معنوي بين تراكيز مستخلص ثمار الحنظل والتراكيب الوراثية للجت في معدل الوزن الطري للكالس، إذ تقوقت أجنة

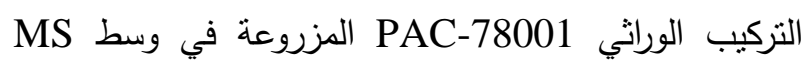

\begin{tabular}{|c|c|c|c|c|}
\hline Stage & Step & & Time & Cycle \\
\hline \multirow[t]{2}{*}{1} & 1 & Denaturation 94c & 3 min & 1 \\
\hline & 1 & Denaturation 94c & $1 \min$ & \\
\hline \multirow[t]{2}{*}{2} & 2 & Annaling 37 c̊ & $1 \min$ & 40 \\
\hline & 3 & Extension $72 \stackrel{\text { c }}{ }$ & $2 \min$ & \\
\hline 3 & 1 & Extension 72 c & $7 \min$ & 1 \\
\hline
\end{tabular}

اعد لوح التحميل باستعمال لوح بلاستيكي شفاف ذي أبعاد

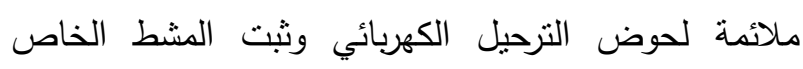

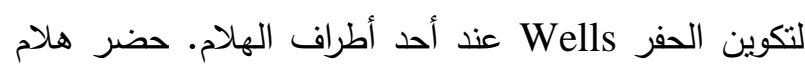
الاكروز بتركيز 2\% وذلك للكثف عن عينات DNA المعزول وذلك باذابة 2 غم من الاكروز في 10 مل من محلول TBE-Buffer بقوة (×1) ويكمل الحجم إلى 100 من مل بإضافة 90 مل من الماء المقطر وسخن مع التحريك

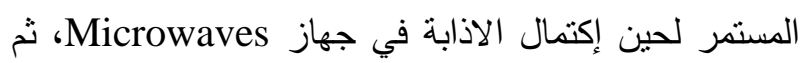
برد إلى درجة حرارة 50-55 مْ وأضيف إليه 5 مايكرولينز

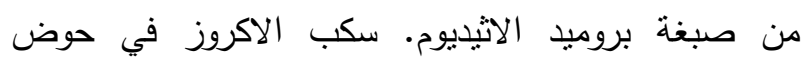
الترحيل بشكل مستمر وهادئ لتجنب تكوين فقاعات هوائية ترك الهام في درجة حرارة المختبر لييرد ويكتسب الصلابة.

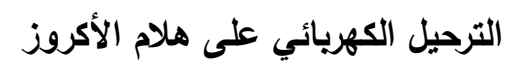
بعد تصلب الهلام رفع المشط بهدوء ووضع هلئ في حوض الاكرون

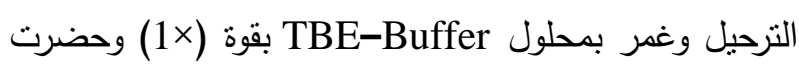
العينات للترحيل.

وزعت العينات على الحفر باستخدام الماصة الدقيقة Micropipette ورحل مع العينات الدليل الحجمي Marker بحجم 100-

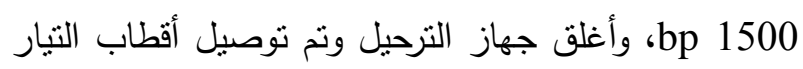
الكهربائي وجهز بفولتية مقدارها 90 فولت وتم الترحيل باتجاه القطب الموجب وبعد مضي ساعتين وعند وصول الصبغة الزرقاء إلى ما قبل نهاية الهلام أوقف الترحيل، فحص الهالام بتعريضه للاشعة فوق البنفسجية بوضعه في في جهاز DNA/RNA UV-Cleaner نانوميتر لروئة حزم DNA وتصويرها لكل نركيب ومعاملة.

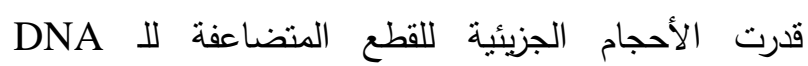

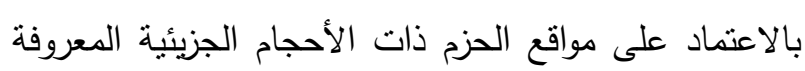
والناتجة من قطع DNA الدليل الحجمي القياسي (27)، رسم المنحنى القياسي بين قيم الاحجام الجزيئية للاليل الحجمي

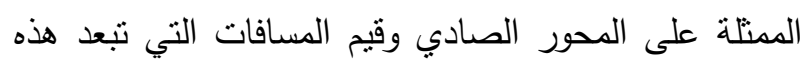


جدول 2. تأثير تراكيز مختلفة من مستخلص ثمار الحنظل في معدل وزن الكالس الطري (ملفم) المستحث من زراعة الأجنة المستأصلة من بذور التركيبين الوراثيين للجت في

وسط MS المضاف إليه 2 ملفم لتر -1 من 2-1-D و0.5 ملفم لتر -1 من .Kin. بعد خمسة أسابيع من الزراعة

\begin{tabular}{|c|c|c|c|}
\hline \multirow[b]{2}{*}{ المعدل } & \multicolumn{2}{|c|}{ التراكيب الور اثية } & تراكيز \\
\hline & المحلي & $\begin{array}{l}\text { PAC- } \\
78001\end{array}$ & مستخلص ثمار \\
\hline 175.20 & 134.80 & 215.60 & $\mathbf{0}$ \\
\hline 176.10 & 132.80 & 219.40 & 75 \\
\hline 205.90 & 157.60 & 254.20 & 150 \\
\hline 161.10 & 119.60 & 202.60 & 225 \\
\hline 135.60 & 103.70 & 167.50 & 300 \\
\hline \multirow[t]{3}{*}{4.51} & \multicolumn{2}{|c|}{6.37} & LSD $_{0.05}$ \\
\hline & 129.70 & 211.86 & المعدل \\
\hline & \multicolumn{2}{|c|}{2.85} & LSD $_{0.05}$ \\
\hline
\end{tabular}

تأثير تراكيز مستخلص ثمار الحنظل والتراكيب الوراثية في وزن الكالس الجاف في وسط MS المضاف إليه 2 ملفم لتر -1 من 2,4-D و0.5 ملغ لتر -1 من مin. بعد خمسة أسابيع من الزراعة يبين الجدول 3 وجود فروقا معنوية بين التراكيب الوراثية للجت في معدل الوزن الجاف للكالس، إذ تفوق التركيب الوراثي PAC-78001 بأعلى معدل للصفة (21.12 ملغر) بينما حقق التركيب الوراثي المحلي أقل معدل للوزن الجاف باف التهاب

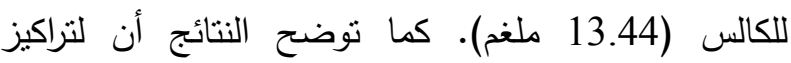
مستخلص ثمار الحنظل المضاف إلى الوسط الغذائي تأثيراً معنوياً في معدل الوزن الجاف للكالس، فقد حقق التركيز 150 مل لتر -1 من مستخلص ثمار الحنظل أعلى معدل

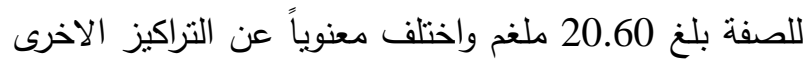

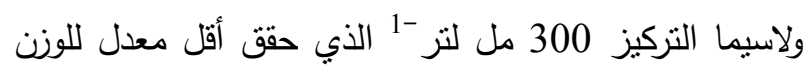
الجاف للكالس (14.65 ملغم)، وقد يعزى نأثير مستخلص ملئ ثمار الحنظل في زيادة معدلات نمو الكالس إلى احتواء

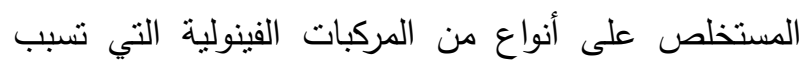
تغايرات وراثية نزيد من نمو الكالس عند استخدامه بالتركيز

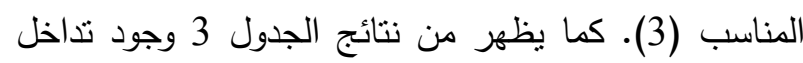
معنوي بين تراكيز مستخلص ثمار الحنظل والتراكيب الوراثية للجت في معدل الوزن الجاف للكالس، إذ اعطى التركيب
المجزز بتركيز 150 مل لتر "من مستخلص ثمار الحنظل

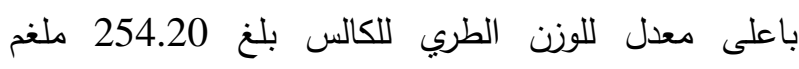
واختلفت معنوياً عن التداخلات الأخرى جميعها التي كان لفان أقلها في أجنة التركيب الوراثي المحلي المزروعة في الوسط الغذائي MS المجهز بتركيز 300 مل لتر -1 من مستخلص

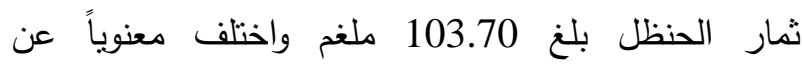
التداخلات الأخرى، ويبين الثكل 3 تأثثر نراكيز مستخلص

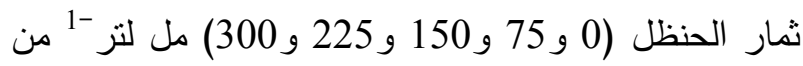
اليمين إلى اليسار بالتتابع في وزن الكالس الطري للتركيب الوراثي PAC-78001 بعد خمسة أسابيع من الزراعة في

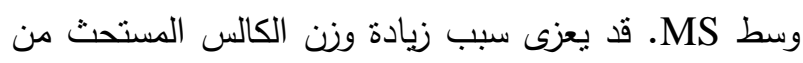

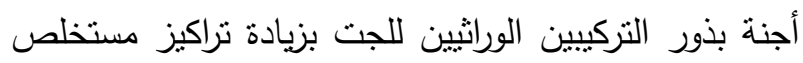
ثمار الحنظل وصولا للتركيز 150 مل لتز -1 قياسا بمعاملة المقارنة إلى أن هذا التركيز كان الأفضل في تشجيع وتحفيز انقسام خلايا الكالس، فضلا عن احتواء مستخلص ثمار الحنظل على مركبات فعالة قد تؤدي اضافتها للوسط الغذائي إلى تحفيز نمو وانقسام الخلايا (23).

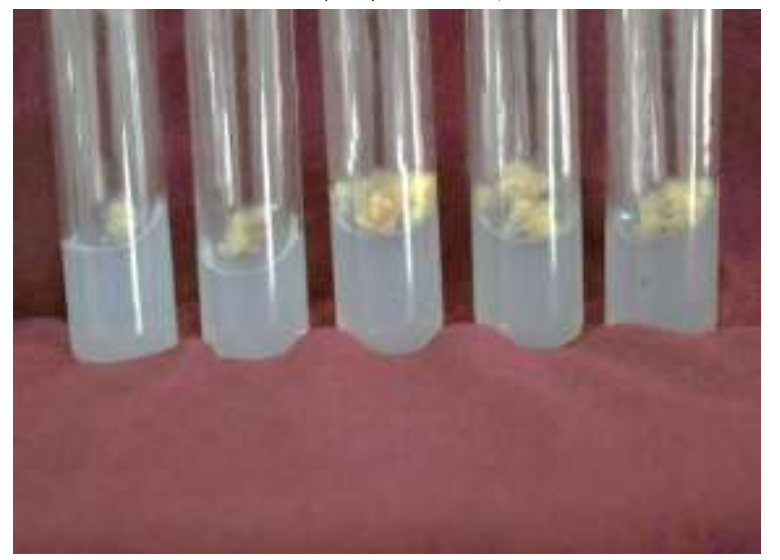

شكل 1. تأثير تراكيز مستخلص ثمار الحنظل من اليمين

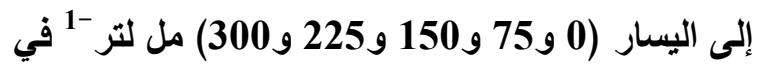

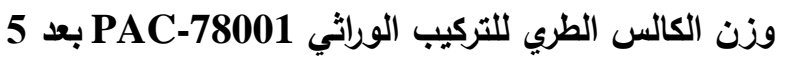
أسابيع من الزراعة لرئي الورياتي

جاءت هذه النتيجة منوافقة مع ما توصل إليه باحثون آخرون من إنها (3 و 7) عند دراستهز على مستخلص ثمار الحنظل. أما

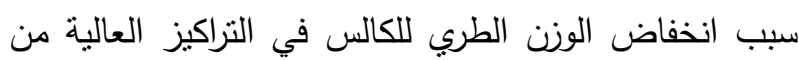

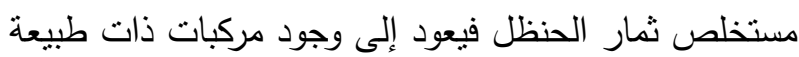
هرمونية إذ تحفز التراكيز القليلة منها نمو الكالس، فيما يكون للتراكيز العالية تأثنير تثثيطي في نمو الكالس كما في دور التئ المركبات التربينية (2 و 3). 
اظهر التركيز 150 مل لتر -1 من مستخلص ثمار الحنظل حزمتين متألقتين حجمها 400 و 550 زوجاً قاعدياً، وأن الحزمة 600 زوجاً قاعدياً اختقت عند التركيز 75 مل لتر -1 من مستخلص ثمار الحنظل وظهرت في التراكيز الأخرى.

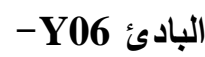

انتج البادئ Y06- ستة مواقع فيزياوية تراوحت أحجامها الجزيئية بين 100-1200 زوج قاعدي في كالس التركيب الوراثي للجت PAC-78001 وسبعة مواقع فيزياوية للتركيب

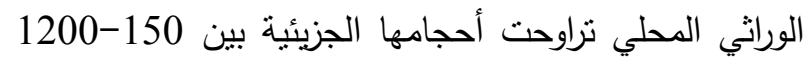
PAC- زوج قاعدي. كانت أقل الحزم في التركيب الوراتي

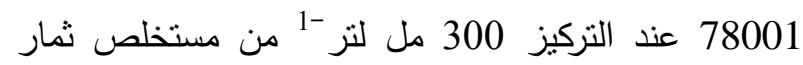

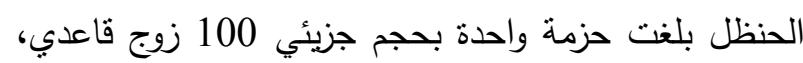
واظهرت في التركيب الوراثي نفسه الحزمة 180 زوجاً قاعدياً

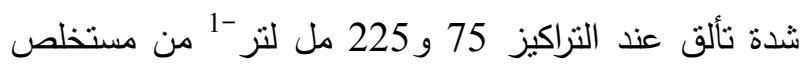

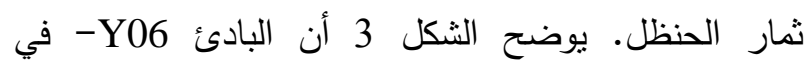
التركيب الوراتي المحلي اعطى أقل عدد حزم بلغ 5 حزم في

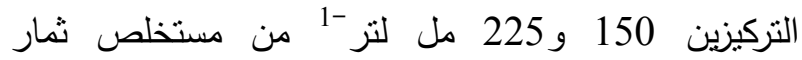
الحنظل، ولم يعطِ كالس التركيب الوراثي المحلي أبي حزم تذكر في تراكيز مستخلص ثمار الحنظل جميعها عند الحزمة 250 زوجاً قاعدياً في حين تحقق ظهور تام للحزم 180

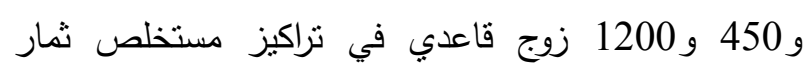
الحنظل جميعها ومعاملة المقارنة.

البادئ OE-12

اعطى البادئ OE-12 خمسة مواقع فيزياوية نراوحت أحجامها الجزيئية بين 300-1200 زوج قاعدي في كالس التركيب الوراثي للجت PAC-78001، أما كالس التركيب

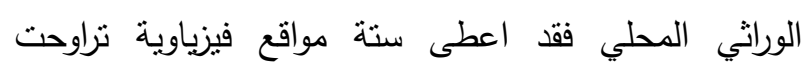
أحجامها الجزيئية بين 320-1200 زوج قاعدي. يبين الثكل 4 أن التركيب الوراثي PAC-78001 المعامل بالتركيز 300 مل لتز -1 من مستخلص ثمار الحنظل اعطى حزمة

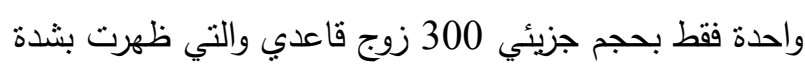

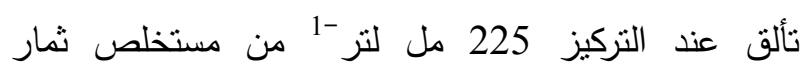

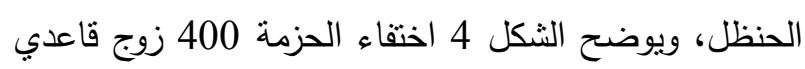
في التركيب الوراثي المحلي المعامل بتراكيز مستخلص ثمار

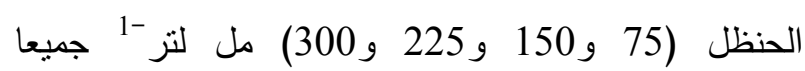
وظهورها في معاملة المقارنة.
الوراثي PAC-78001 المزروع في وسط MS المجز بالتركيز 150 مل لتر -1 من مستخلص ثمار الحنظل أعلى فلى فئ معدل للوزن الجاف للكالس بلغ 24.80 ملغم واختلف معنوياً عن بقية التذاخلات التي حقق فيها التركيب الوراثي المحلي المزروع في وسط MS المجز بالتركيز 300 مل لتز -1 من فن فئ

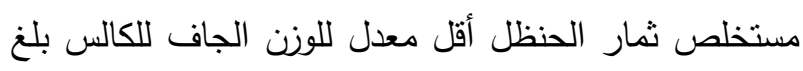
11.60 ملغم واختلف معنوياً عن التداخلات الأخرى جميعها. جدول 3. تأثير تراكيز مختلفة من مستخلص ثمار الحنظل

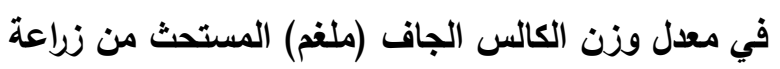

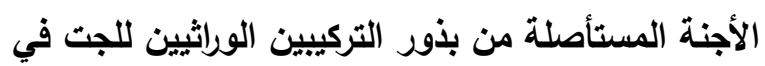

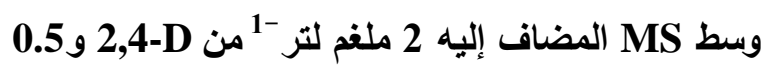
ملفم لتر -1 من .Kin. بعد خمسة أسابيع من الزراعة

\begin{tabular}{|c|c|c|c|}
\hline \multirow{2}{*}{ المعدل } & \multicolumn{2}{|c|}{ التراكيب الوراثية } & تراكيز \\
\hline & المحلي & PAC-78001 & (مل لتر -1) \\
\hline 17.00 & 13.40 & 20.60 & $\mathbf{0}$ \\
\hline 17.05 & 12.90 & 21.20 & 75 \\
\hline 20.60 & 16.40 & 24.80 & 150 \\
\hline 17.10 & 12.90 & 21.30 & 225 \\
\hline 14.65 & 11.60 & 17.70 & 300 \\
\hline \multirow[t]{3}{*}{0.65} & \multicolumn{2}{|r|}{0.91} & LSD $_{0.05}$ \\
\hline & 13.44 & 21.12 & المعدل \\
\hline & \multicolumn{2}{|r|}{0.41} & $\mathbf{L S D}_{0.05}$ \\
\hline
\end{tabular}

انتج البادئ Y07- تسعة مواقع فيزياوية نراوحت أحجامها

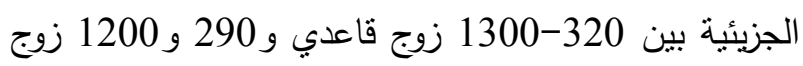
قاعدي لكالس التركيبين الوراثيين للجت والمحلي بالتتابع. يبين الثكل 2 أنه في التركيب الوراثي PAC-78001 اختفت الحزم جميعها عند التركيز 300 مل فل فئن لتر -1 من مستخلص ثمار الحنظل، في حين اظهر التركيز 225 مل لنز -1 من مستخلص ثمار الحنظل الحزم المتألقة

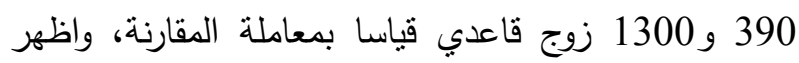
التركيز 150 مل لتز -1 من مستخلص ثمار الحنظل الحزمة المتألقة 390 زوجاً قاعدياً. يوضح الثكل ملتر 2 أن أقل الحزم بلغ 7 حزم في كالس التركيب الوراثي المحلي للجت عند استخدام البادئ Y07 - في معاملتي 75 و من مستخلص ثمار الحنظل، وعند التركيب الوراثي المحلي 
وحيدة متألقة بوزن جزيئي 850 زوجاً قاعدياً عند التركيز 225 مل لتر -1 من مستخلص ثمار الحنظل. البادئ Y10 انتج البادئ Y10- تسعة مواقع فيزياوية تراوحت أحجامها بين 100-1200 زوج قاعدي لكالس التركيب الوراثي PAC-78001 المعامل بتراكيز مختلفة من مستخلص ثمار الحنظل، وثمانية مواقع فيزياوية للتركيب الوراثي المحلي تراوحت أحجامها بين 380 - 1300 زوج قاعدي. كانية كان أقل عدد للحزم في كالس الجت المستحث من التركيب الوراثي

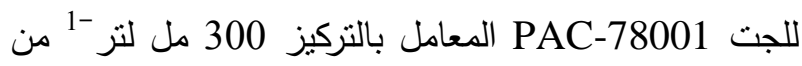
مستخلص ثمار الحنظل بلغ حزمنين وتميز هذا التركيب

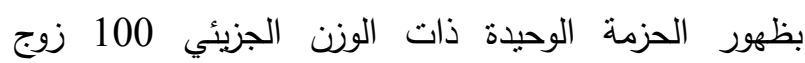

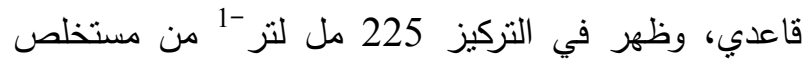
ثمار الحنظل حزمة واحدة متألقة بوزن جزيئي 470 زوجاً قاعدياً، ويلاحظ من الثكل 7 أنه في التركيب الوراثي

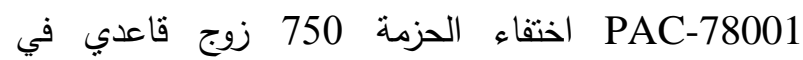
التركيزين 75 و 150 مل لتر -1 من مستخلص ثمار الحنظل، وكذلك اختفاء الحزمة 700 زوج قاعدي عند التركيزين 75 225 مل لتز -1 من مستخلص ثمار الحنظل، كما يبين الثكل 20 أن الحزمة ذات الوزن الجزيئي 520 زوجاً قاعدياً ظهرت في تراكيز مستخلص ثمار الحنظل جميعها. أما التركيب الوراثي المحلي فيلاحظ من الثكل 7 أن الحزمة ذات الوزن الجزيئي 460 زوجاً قاعدياً قد اختفت في التركيز 300 مل لتر-1 من مستخلص ثمار الحنظل، وأن الحزمة 800

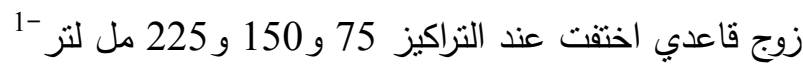
من مستخلص ثمار الحنظل، كما اختقت الحزمة 500 زوج قاعدي عند التركيز 150 مل لتر -1 من مستخلص ثمار الثمار الحنظل.

البادئ A-16

ارتبط البادئ A-16 بالتتابعات المكملة له في قالب DNA إذ بلغ عدد الحزم خمسة مواقع فيزياوية تراوحت أحجامها بين

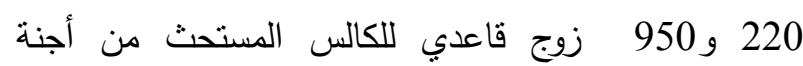
التركيب الوراثي

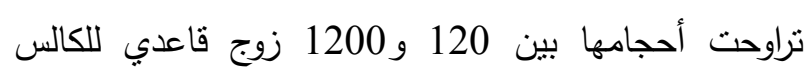
المستحث من أجنة التركيب الوراثي المحلي. اظهر الكالس المستحث من التركيب الوراتي
البادئ C-08

اظهر البادئ C-08 نسعة مواقع فيزياوية نراوحت أحجامها بين 90 و 1200 زوج قاعدي لكالس التركيب الوراتي - PAC 78001 المعامل بتراكيز مستخلص ثمار الحنظل المختلفة،

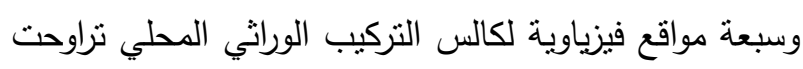
أحجامها بين 120 و 1300 زوج قاعدي. كان أقل عدد للحزم في التركيب الوراتي 300 PAC-78001 المعامل بالتركيز مل لتز -1 من مستخلص ثمار الحنظل بلغ حزمتين نزاوحت

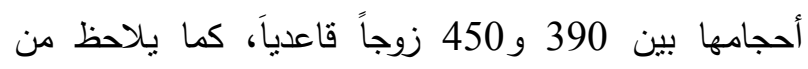
الثكل 5 اختفاء الحزمة ذات الوزن الجزيئي 210 زوج قاعدي في كالس التركيب الوراثي PAC-78001 المعامل بالتراكيز 150 و 225 و300 مل لنري -1 من مستخلص ثمار الحئ الحنظل. يوضح الثكل 5 أن الحزمة ذات الوزن الجزيز لدئي 320 زوجاً قاعدياً اختقت في كالس التركيب الوراثي المحلي العامل بتراكيز مستخلص ثمار الحنظل جميعها ولم تظهر إلا في معاملة المقارنة.

البادئ D-10

اظهر البادئ D-10 تسعة مواقع فيزياوية نراوحت أحجامها الجزيئية بين 180-1300 زوج قاعدي لكالس التركيبين الوراثيين للجت PAC-78001 والمحلي بالتتابع. كان أقل بلت عد عد للحزم في كالس التركيب الوراثي PAC-78001 المعامل بالتركيز 300 مل لتز -1 من مستخلص ثمار الحنظل

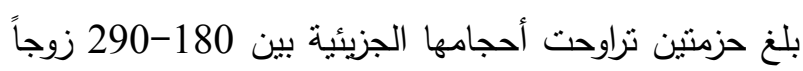

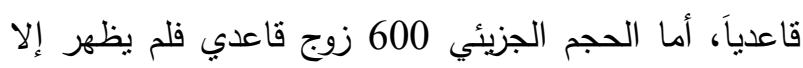
في التركيز 150 مل لتز -1 من مستخلص ثمار الحنظل،

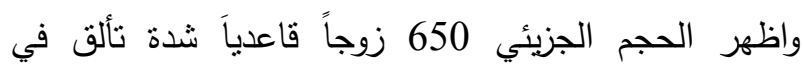
التراكيز 75 و150 و225 مل لنر-1 من مستخلص ثمار الحنظل، كما يلاحظ أن الحزمة 490 زوجاً قاعدياً ظهرت

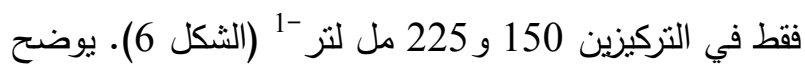
الثكل 6 أن كالس التركيب الوراثي المحلي للجت الظهر 7 لتربن

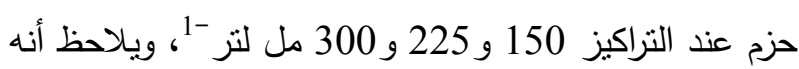
عند التركيز 300 مل لنز -1 من مستخلص ثمار الحنظل اختقاء الحزم 850 و 3050 زون فن فاعدي، وكذلك في التركيز

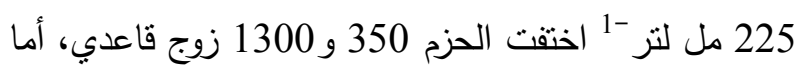
في التركيز 150 مل لتز -1 من مستخلص ثمار الحنظل فقد فئ اختقت الحزم 950 و 1300 زوج قاعدي، وظهرت حزمة 
حزما متألقة واختلفت عن بقية الحزم الأخرى. أما التركيب الوراثي المحلي فكانت للحزمة ذات الوزن الجزيئي 1200 زوج قاعدي شدة تألق في تراكيز مستخلص ثمار الحنظل

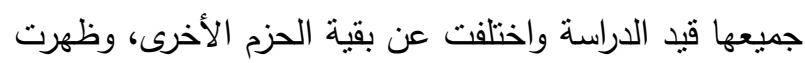
شدة التألق في معاملة المقارنة عند الوزن الجزيئي نفسه

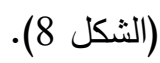

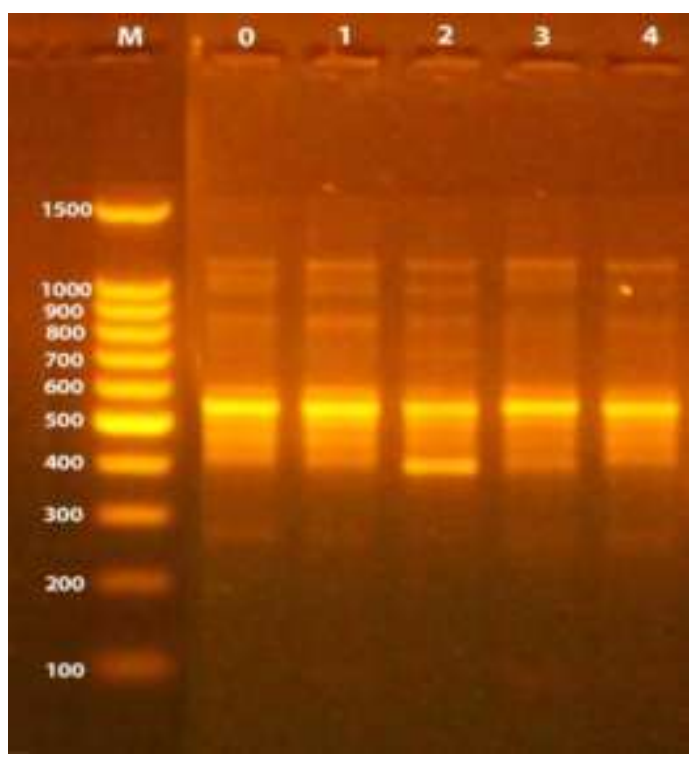

المحلي

بالتركيز 300 مل لتر -1 من مستخلص ثمار الحنظل أقل معدل للحزم بلغ 2 حزمة، وتميز هذا التركيب بظهور الحزمة

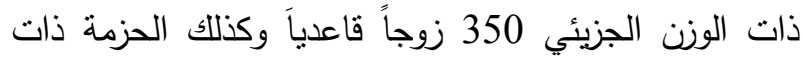
الوزن الجزيئي 220 زوجاً قاعدياً والتي تميزت بثدة نألقها،

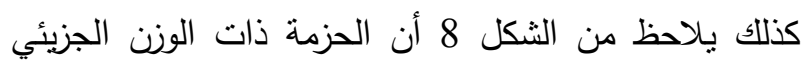
950 زوجاً قاعدياً والتي ظهرت في تراكيز مستخلص ثمار

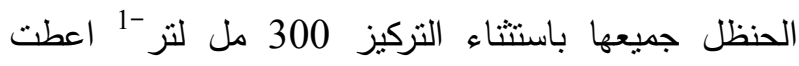

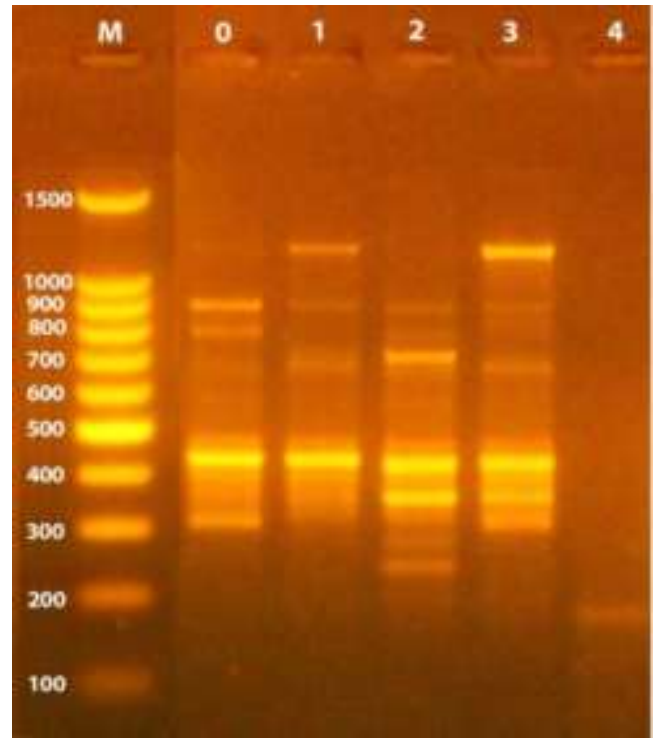

\section{PAC-78001}

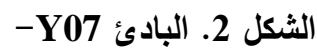

DNA ladder الاليل الحجمي القياسي المتمثل بـ M =0

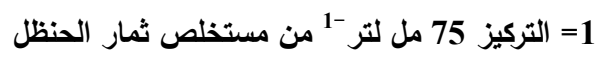

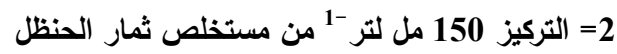

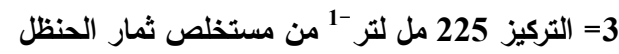

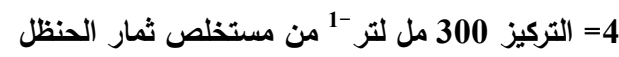

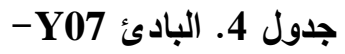

\begin{tabular}{|c|c|c|c|c|c|c|c|c|c|c|c|}
\hline \multicolumn{12}{|c|}{ التراكيب الوراثية للجت } \\
\hline & ملفم لتر -1) & ثار المحي & 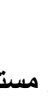 & & \multirow[t]{2}{*}{ الجزيئي } & \multicolumn{5}{|c|}{ PAC-78001 } & \multirow{2}{*}{ الجزيئي } \\
\hline 300 & 225 & 150 & 75 & $\mathbf{0}$ & & 300 & 225 & 150 & 75 & $\mathbf{0}$ & \\
\hline 1 & 1 & 1 & 1 & 1 & 1200 & $\mathbf{0}$ & $* 1$ & $\mathbf{0}$ & 1 & $\mathbf{0}$ & 1300 \\
\hline 0 & 1 & 1 & 1 & 1 & 1000 & 0 & 1 & 1 & 1 & 1 & 900 \\
\hline 1 & 1 & 1 & 1 & 1 & 890 & 0 & 1 & 1 & 1 & 1 & 700 \\
\hline 1 & 1 & 1 & $\mathbf{0}$ & 1 & 600 & $\mathbf{0}$ & 1 & 1 & 1 & 1 & 490 \\
\hline$* 1$ & ${ }^{*} 1$ & $* 1$ & ${ }^{*} 1$ & $* 1$ & 550 & $\mathbf{0}$ & $* 1$ & $* 1$ & $* 1$ & $* 1$ & 450 \\
\hline 1 & 1 & 1 & 1 & 1 & 500 & $\mathbf{0}$ & 1 & 1 & 1 & 1 & 410 \\
\hline 1 & 1 & 1 & 1 & 1 & 450 & $\mathbf{0}$ & $* 1$ & ${ }^{*} 1$ & 1 & 1 & 390 \\
\hline 1 & 1 & ${ }^{*} 1$ & 1 & 1 & 400 & $\mathbf{0}$ & 1 & 1 & 1 & 1 & 350 \\
\hline $\mathbf{0}$ & $\mathbf{0}$ & $\mathbf{0}$ & $\mathbf{0}$ & 1 & 290 & $\mathbf{0}$ & 1 & 1 & 1 & 1 & 320 \\
\hline
\end{tabular}

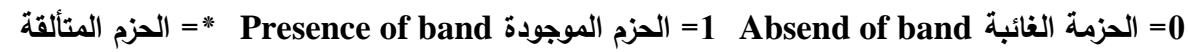




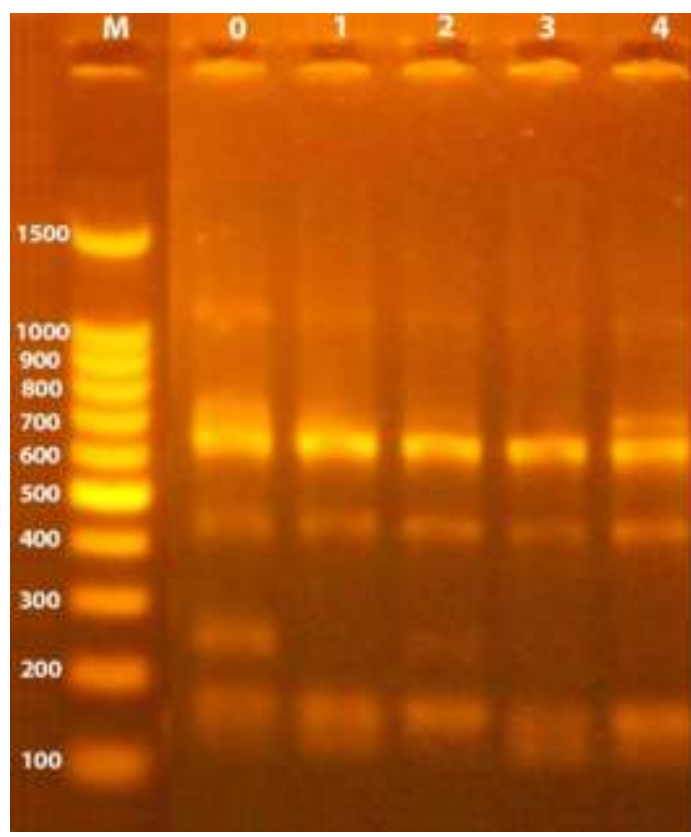

المحلي

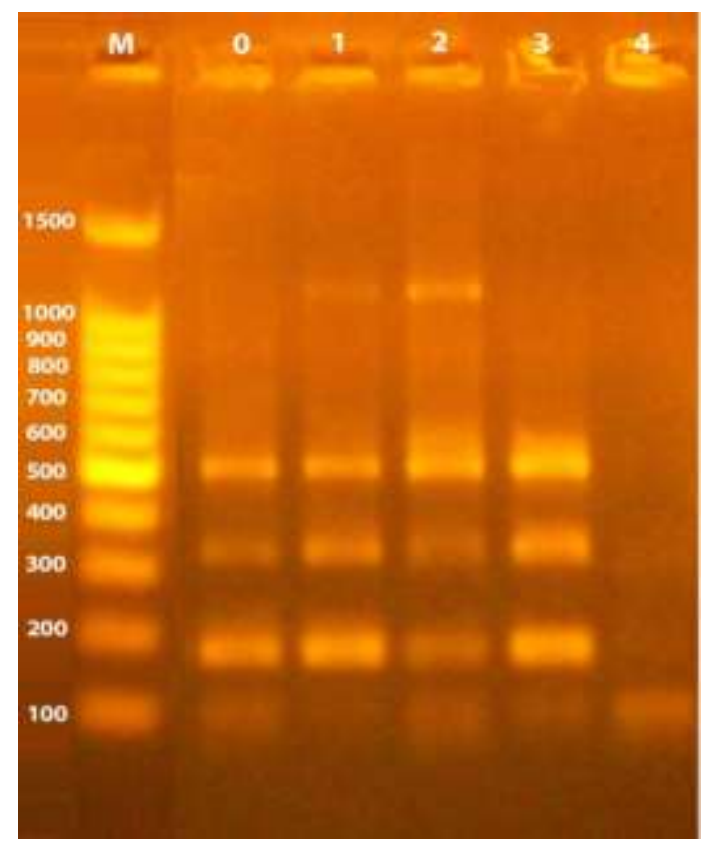

PAC-78001

الشكل 3. البادئ Y06-

DNA ladder الاليل الحجمي القياسي المتمثل ب =

0 = معاملة المقارنة

1= التركيز 75 مل لتر -1 من مستخلص ثمار الحنظل

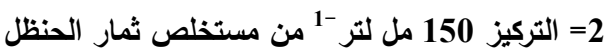

3= التركيز 225 مل لتر -1 من مستخلص ثمار الحنظل

4= التركيز 300 مل لتز -1 من مستخلص ثمار الحنظل من ملئ

جدول 5. البادئ Y06 -

\begin{tabular}{|c|c|c|c|c|c|c|c|c|c|c|c|}
\hline \multicolumn{12}{|c|}{ التراكيب الوراثية للجت } \\
\hline & (ملفم & المحلي & ستخظ & & \multirow{2}{*}{ الجزئي } & \multicolumn{5}{|c|}{ PAC-78001 } & \multirow{2}{*}{ الجزيئي } \\
\hline 300 & 225 & 150 & 75 & $\mathbf{0}$ & & 300 & 225 & 150 & 75 & $\mathbf{0}$ & \\
\hline 1 & 1 & 1 & 1 & 1 & 1200 & $\mathbf{0}$ & $\mathbf{0}$ & 1 & 1 & $\mathbf{0}$ & 1200 \\
\hline 1 & $\mathbf{0}$ & 1 & 1 & 1 & 700 & $\mathbf{0}$ & $\mathbf{0}$ & 1 & $\mathbf{0}$ & $\mathbf{0}$ & 600 \\
\hline$* 1$ & $* 1$ & $* 1$ & $* 1$ & $* 1$ & 650 & $\mathbf{0}$ & $* 1$ & $* 1$ & $* 1$ & $* 1$ & 500 \\
\hline 1 & 1 & 1 & 1 & 1 & 450 & $\mathbf{0}$ & 1 & 1 & 1 & 1 & 350 \\
\hline $\mathbf{0}$ & $\mathbf{0}$ & $\mathbf{0}$ & $\mathbf{0}$ & 1 & 250 & $\mathbf{0}$ & $* 1$ & $* 1$ & $* 1$ & 1 & 180 \\
\hline 1 & 1 & 1 & 1 & 1 & 180 & 1 & 1 & 1 & 1 & 1 & 100 \\
\hline 1 & 1 & $\mathbf{0}$ & 1 & 1 & 150 & & & & & & \\
\hline
\end{tabular}




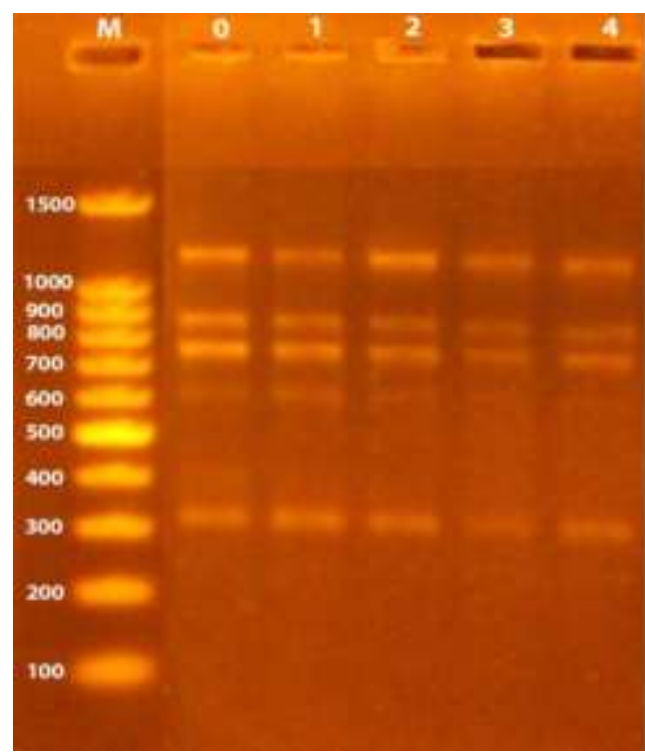

لمحلي

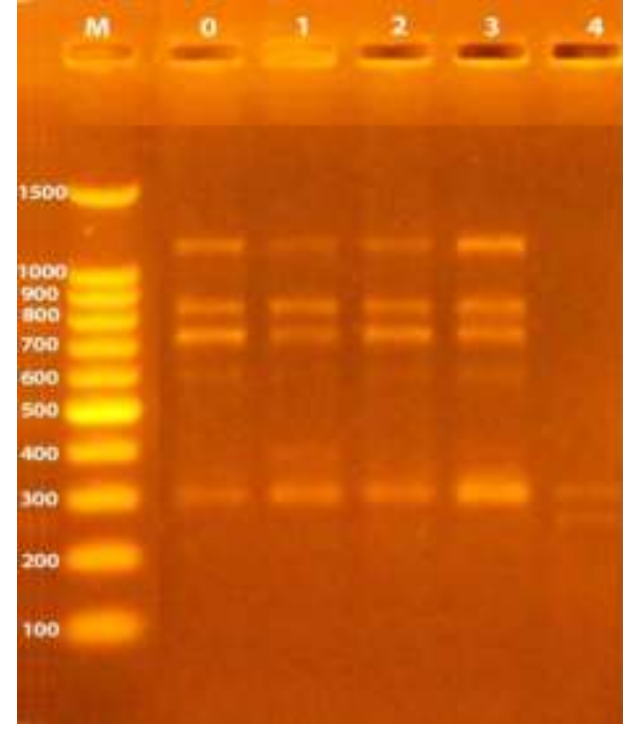

PAC-78001

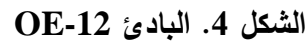

$$
\begin{aligned}
& \text { DNA ladder الدليل الحجمي القياسي المتمثل ب = M } \\
& \text { =0 } \\
& \text { 1= التركيز } 75 \text { مل لتر -1 من مستخلص ثمار الحنظل }
\end{aligned}
$$

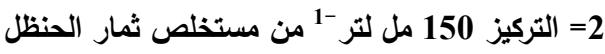

\begin{tabular}{|c|c|c|c|c|c|c|c|c|c|c|c|}
\hline \multicolumn{12}{|c|}{ التراكيب الوراثية للجت } \\
\hline & (ملغم נ) & ثمار الدي & مست & & \multirow[t]{2}{*}{ الجزيئي } & \multicolumn{5}{|c|}{$\begin{array}{c}\text { PAC-78001 } \\
\text { تراكيز مستخلص ثمار الحنظل (ملفم لتر-1) }\end{array}$} & \multirow[t]{2}{*}{ الجزيئي } \\
\hline 300 & 225 & 150 & 75 & 0 & & 300 & 225 & 150 & 75 & 0 & \\
\hline 1 & 1 & 1 & 1 & 1 & 1200 & $\mathbf{0}$ & 1 & 1 & 1 & 1 & 1200 \\
\hline 1 & 1 & 1 & 1 & 1 & 900 & 0 & 1 & 1 & 1 & 1 & 850 \\
\hline 1 & 1 & 1 & 1 & 1 & 750 & 0 & 1 & 1 & 1 & 1 & 750 \\
\hline 1 & 1 & 1 & 1 & 1 & 620 & 0 & 1 & 1 & 1 & 1 & 600 \\
\hline 0 & 0 & 0 & $\mathbf{0}$ & 1 & 400 & 1 & $* 1$ & 1 & 1 & 1 & 300 \\
\hline 1 & 1 & 1 & 1 & 1 & 320 & & & & & & \\
\hline
\end{tabular}

$$
\begin{aligned}
& \text { 3= التركيز } 225 \text { مل لتر -1 من مستخلص ثمار الحنظل } \\
& \text { 4= التركيز } 300 \text { مل لتر -1 من مستخلص ثمار الحنظل من منلئ }
\end{aligned}
$$

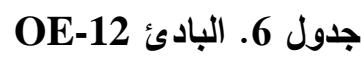




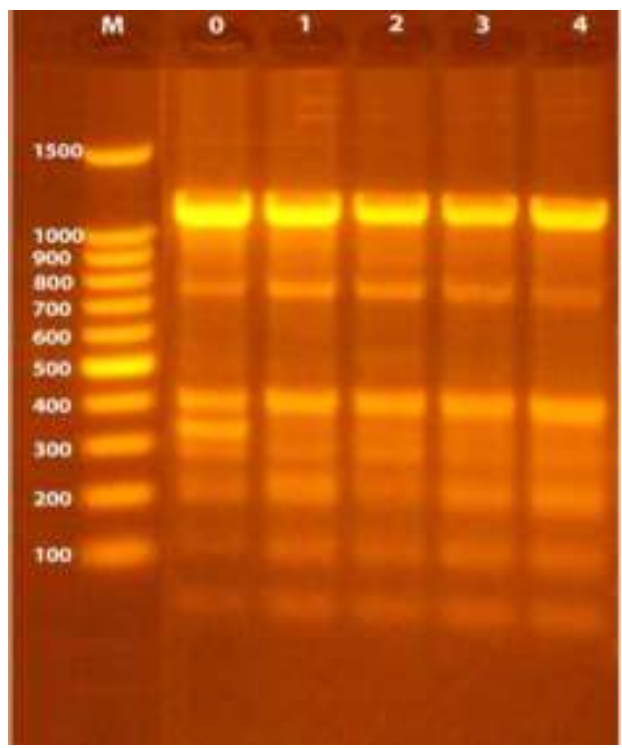

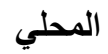

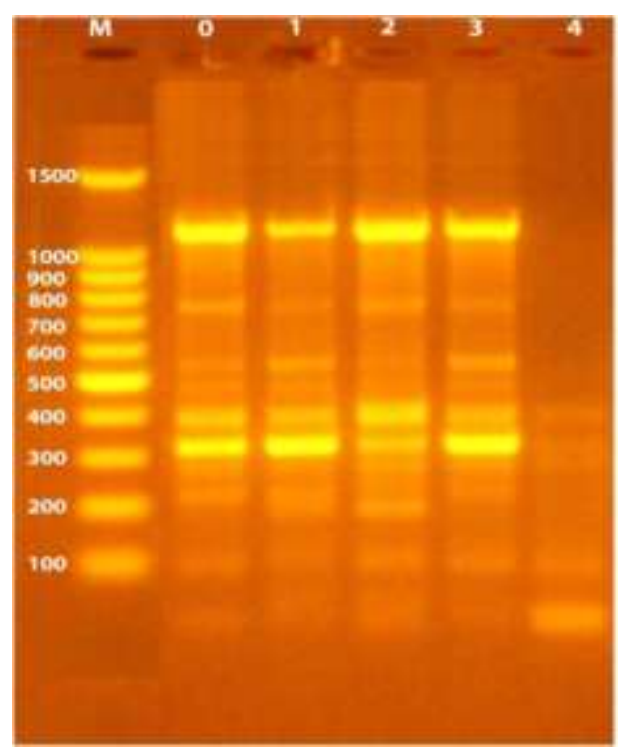

PAC-78001

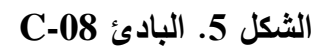

DNA ladder الاليل الحجمي القياسي المتمثل ب = M =0

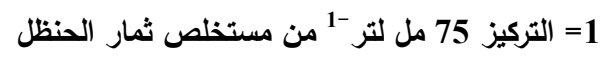

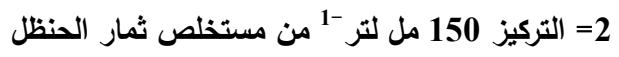

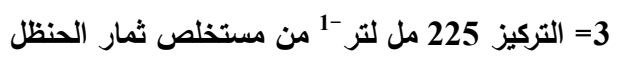

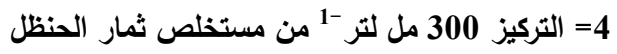

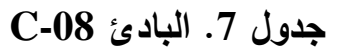

\begin{tabular}{|c|c|c|c|c|c|c|c|c|c|c|c|}
\hline \multicolumn{12}{|c|}{ التراكيب الوراثية للجت } \\
\hline \multicolumn{5}{|c|}{ ثُمار الحنظل (ملف لتر -1) } & \multirow{2}{*}{ الجزيئي } & \multicolumn{5}{|c|}{ PAC-78001 } & \multirow{2}{*}{ الجزيئي } \\
\hline 300 & (مل2م & (150 & (5) & 0 & & 300 & (م25 (225) & 150 & 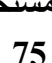 & 0 & \\
\hline$* 1$ & *1 & *1 1 & $* 1$ & $* 1$ & 1300 & 0 & $* 1$ & *1 & *1 1 & *1 1 & 1200 \\
\hline 1 & 1 & 1 & 1 & 1 & 750 & 0 & 1 & 1 & 1 & 1 & 750 \\
\hline 1 & 1 & 1 & 1 & 1 & 400 & 0 & 1 & 1 & 1 & 1 & 550 \\
\hline 0 & 0 & 0 & 0 & 1 & 320 & 0 & 1 & 1 & 1 & 1 & 450 \\
\hline 1 & 1 & 1 & 1 & 1 & 280 & 1 & 1 & $* 1$ & 1 & 1 & 390 \\
\hline 1 & 1 & 1 & 1 & 1 & 200 & 1 & $* 1$ & 1 & $* 1$ & $* 1$ & 320 \\
\hline \multirow[t]{3}{*}{1} & 1 & 1 & 1 & 1 & 120 & 0 & 1 & 1 & 1 & 1 & 290 \\
\hline & & & & & & 0 & 0 & 0 & 1 & 1 & 210 \\
\hline & & & & & & 0 & 1 & 1 & 1 & 1 & 90 \\
\hline
\end{tabular}

= = الحزمة الغائبة Presence of band 1 Absend of band = الحزم الموجودة الحزم المتألقة 


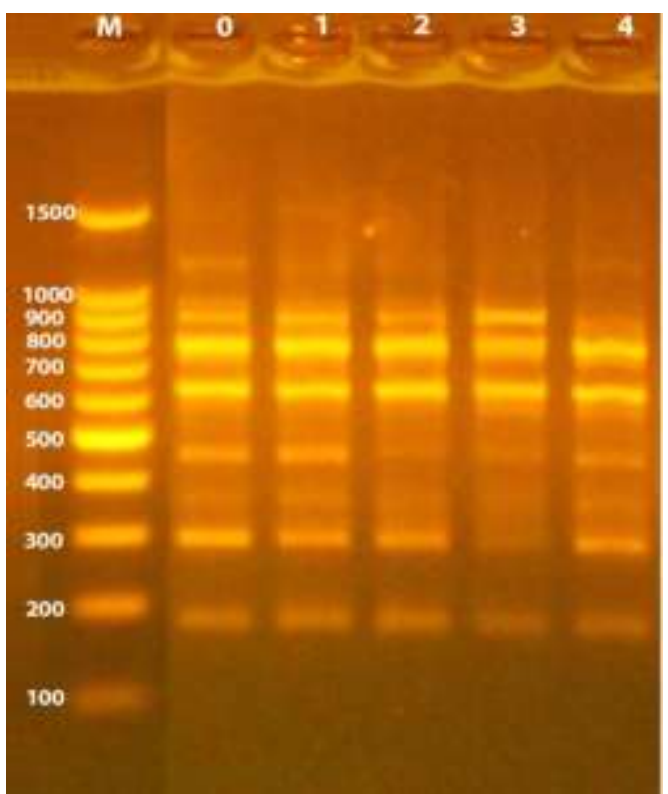

المحلي

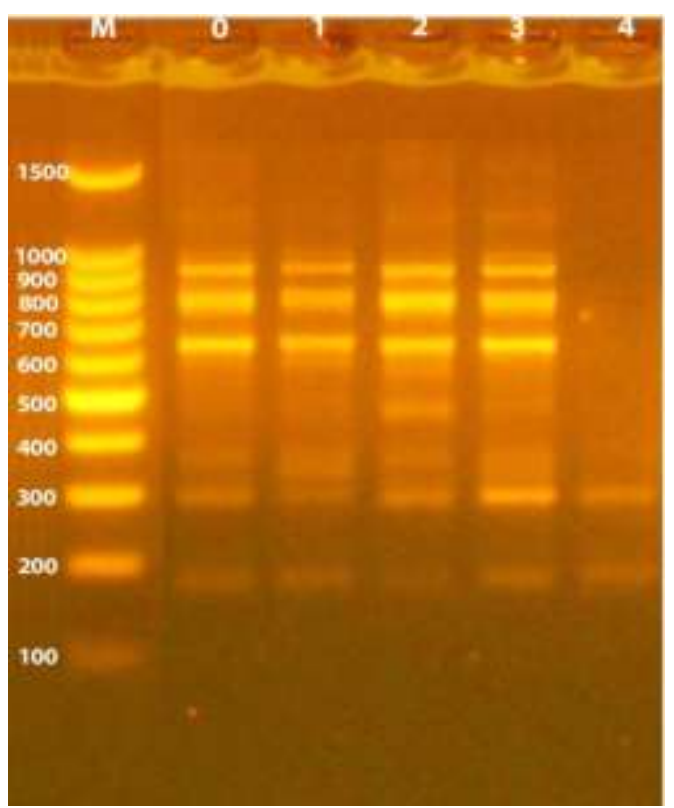

PAC-78001

الثكل 6-10 البادئ D-10

DNA ladder الدليل الحجمي القياسي المتمثل بـ =M

=0

=1 التركيز 75 مل لتر -1 من مستخلص ثمار الحنظل

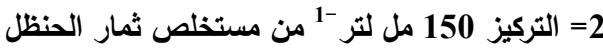

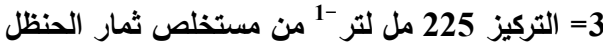

4= التركيز 300 مل لتر -1 من مستخلص ثمار الحنظل من من من من

جدول 8.10. البادئ

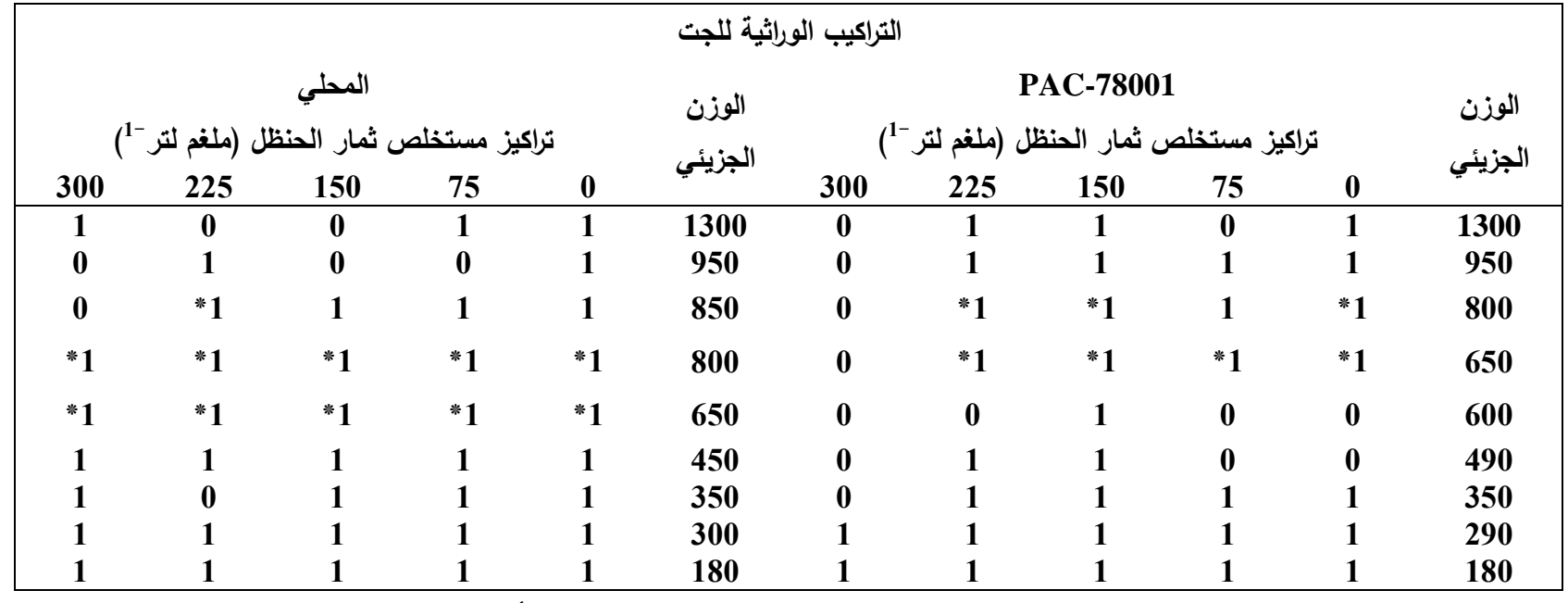

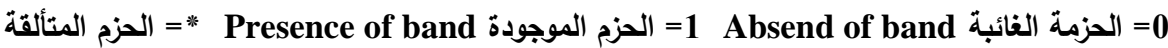




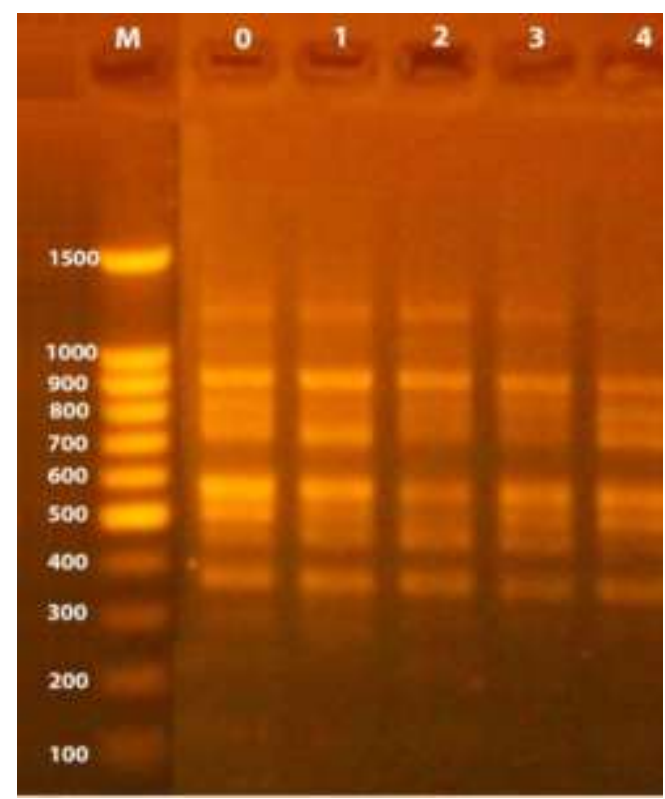

المحلي

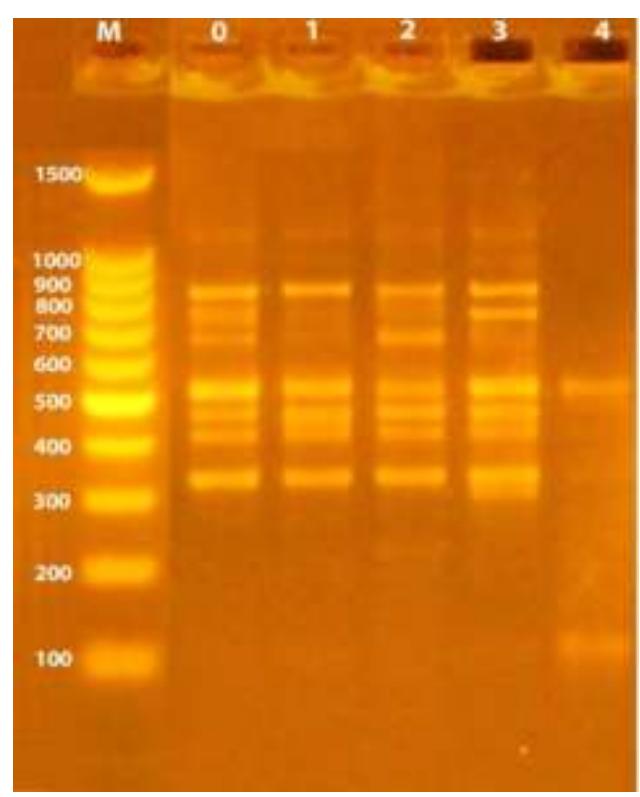

PAC-78001

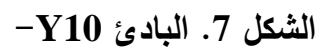

DNA ladder الاليل الحجمي القياسي المتمثل ب =0

1 = التركيز 75 مل لتر -1 150 من مستخلص ثمارن الحنظل

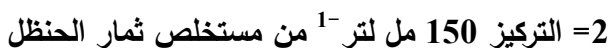

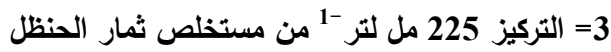

4= التركيز 300 مل لتر -1 من مستخلص ثمار الحنظل من فين

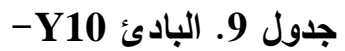

\begin{tabular}{|c|c|c|c|c|c|c|c|c|c|c|c|}
\hline \multicolumn{11}{|c|}{ التراكيب الوراثية للجت } & \multirow{4}{*}{ الجزيئي } \\
\hline & & المحلي & & & \multirow{3}{*}{ الجزيئي } & \multirow{2}{*}{\multicolumn{5}{|c|}{$\begin{array}{c}\text { PAC-78001 } \\
\left.\text { تراكيز منتخل ثمار الحنظل (ملغ لتر }{ }^{-1}\right)\end{array}$}} & \\
\hline \multicolumn{5}{|c|}{ تراكيز مستخلص ثمار الحنظل (ملفم لتر +1) } & & & & & & & \\
\hline 300 & 225 & 150 & 75 & $\mathbf{0}$ & & 300 & 225 & 150 & 75 & $\mathbf{0}$ & \\
\hline 1 & 1 & 1 & 1 & 1 & 1300 & 0 & 1 & 1 & 1 & 1 & 1200 \\
\hline 1 & 1 & 1 & 1 & 1 & 900 & 0 & 1 & 1 & 1 & 1 & 800 \\
\hline 1 & 0 & 0 & 0 & 1 & 800 & 0 & 1 & 0 & $\mathbf{0}$ & 1 & 750 \\
\hline 1 & 1 & 1 & 1 & 1 & 710 & 0 & 0 & 1 & $\mathbf{0}$ & 1 & 700 \\
\hline 1 & 1 & 1 & 1 & 1 & 580 & 1 & 1 & 1 & 1 & $* 1$ & 520 \\
\hline 1 & 1 & $\mathbf{0}$ & 1 & 1 & 500 & $\mathbf{0}$ & $* 1$ & 1 & 1 & 1 & 470 \\
\hline 0 & 1 & 1 & 1 & 1 & 460 & 0 & 1 & 1 & 1 & 1 & 410 \\
\hline 1 & 1 & 1 & 1 & 1 & 380 & $\mathbf{0}$ & 1 & 1 & 1 & 1 & 320 \\
\hline & & & & & & 1 & 0 & 0 & 0 & 0 & 100 \\
\hline
\end{tabular}

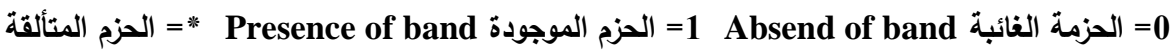




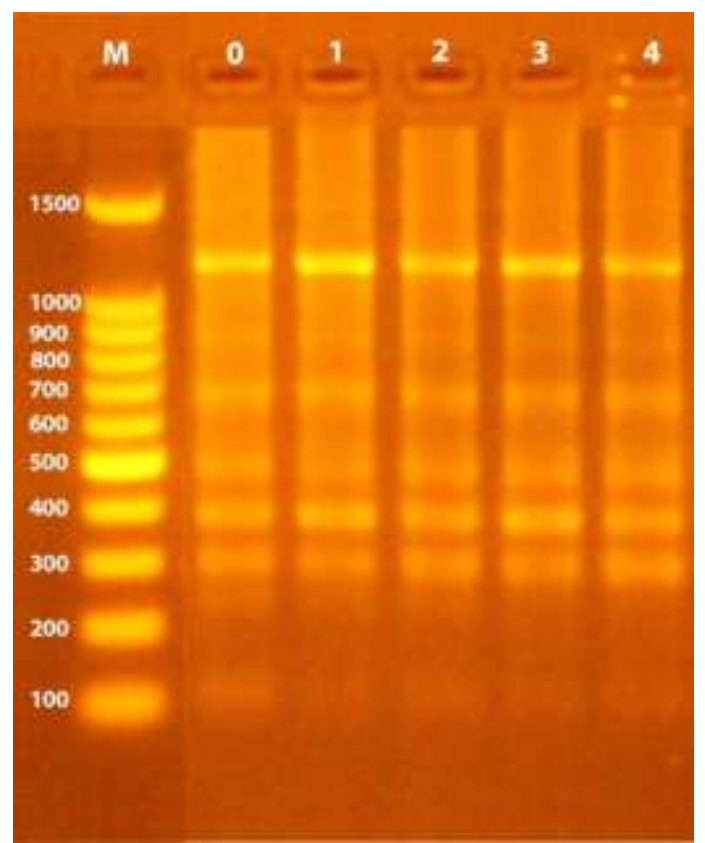

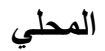

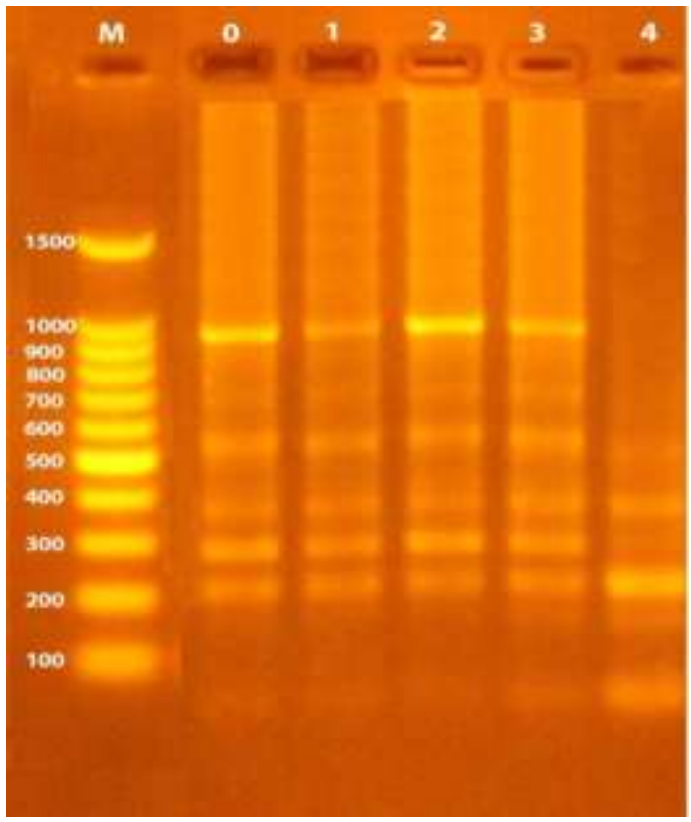

PAC-78001

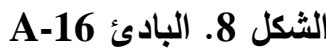

DNA ladder الاليل الحجمي القياسي المتمثل بـ

0 =0 معاملة المقارنة

=1 التركيز 75 مل لتر -15 من مستخلص ثمار الحنظل

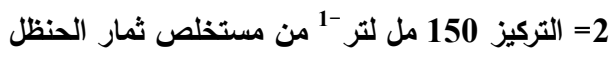

3= التركيز 225 مل لتر -1 من مستخلص ثمار الحنظل

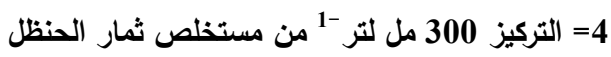

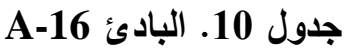

\begin{tabular}{|c|c|c|c|c|c|c|c|c|c|c|c|}
\hline \multicolumn{12}{|c|}{ التراكيب الوراثية للجت } \\
\hline \multirow{2}{*}{\multicolumn{5}{|c|}{ تراكيز مستخلص ثمار الحنظل (ملفم لتر -1) }} & \multirow{3}{*}{ 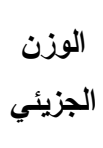 } & \multicolumn{5}{|c|}{ PAC-78001 } & \multirow{3}{*}{ الجزيئي } \\
\hline & & & & & & & (ملفم ل & 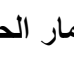 & 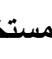 & & \\
\hline 300 & 225 & 150 & 75 & $\mathbf{0}$ & & 300 & 225 & 150 & 75 & $\mathbf{0}$ & \\
\hline$* 1$ & $* 1$ & $* 1$ & $* 1$ & $* 1$ & 1200 & 0 & ${ }^{* 1} 1$ & $* 1$ & $* 1$ & $* 1$ & 950 \\
\hline 1 & 1 & 1 & 1 & 1 & 850 & 0 & 1 & 1 & 1 & 1 & $\mathbf{5 5 0}$ \\
\hline 1 & 1 & 1 & 1 & 1 & 700 & 1 & 1 & 1 & 1 & 1 & 350 \\
\hline 1 & 1 & 1 & 1 & 1 & 490 & 0 & 1 & 1 & 1 & 1 & 290 \\
\hline 1 & 1 & 1 & 1 & 1 & 390 & *1 1 & 1 & 1 & 1 & 1 & 220 \\
\hline 1 & 1 & 1 & 1 & 1 & 300 & & & & & & \\
\hline 1 & 1 & 1 & 1 & 1 & 250 & & & & & & \\
\hline 1 & 1 & 1 & 1 & 1 & 120 & & & & & & \\
\hline
\end{tabular}

= = الحزمة الغائبة Presence of band Absend of band الحزم الموجودة = الحزم المتألقة

ظهور حزم جديدة في تراكيز مستخلص الحنظل للكالس

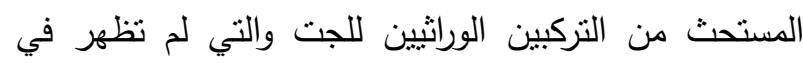
معاملة المقارنة للكالس المستحث من كلا التركيبين الوراثيين للجت. اوضحت النتائج أن نواتج التفاعل لعدد من الحزم

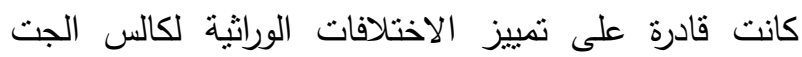
المعرض للتركيز 300 مل لتز -1 من مستخلص ثمار الحنظل
نتائج تفاعل البوادئ اظهرت نتائج RAPD-PCR للبوادئ المختبرية اختلافات واضحة بين نراكيز مستخلص ثمار الحنظل للكالس المستحث

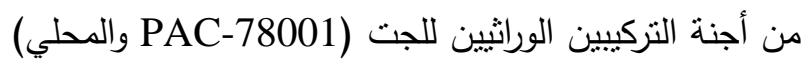
قيد الدراسة من خلال عدد الحزم الناتجة ومواقعها الفيزياوية وشدة تألقها مع وجود اختلافات بين البوادئ ذاتها فضلا عن عن 
Jain; D. S. Brar and S. Ahloowalia (Edrs.). Somaclonal Variation and Induced Mutation in Crop Improvement. Kluwer Academic Publ., London. UK. p. 15-37.

7. Delazar, A.; S. Gibbons; A. R. Kosari; H. Nazemiyeh; M. Modarresi; L. Nahar and S. D. Sarker. 2006. Flavone C-glycosides and cucurbitacin glycosides from Citrullus colocynthis. DARU. 14: 109-114.

8. Dellaporta, S. L.; J. Wood and J. B. Hicks. 1983. A plant DNA micro preparation. Plant Mol. Rep.1: 19-21.

9. Echt, C. S.; L. A. Erdahl and T. J. McCoy. 1992. Genetic segregation of random amplified polymorphie DNA in diploid cultivated alfalfa Gemome. 22: 84-78.

10. Elsahookie, M. M. 2013. Breeding Crops for Abiotic Stress: A molecular Approach and Epigenetic. Coll. of Agric., Univ. of Baghdad. pp. 244.

11. Elsahookie, M. M. and K. M. Wuhaib. 1990. Experiment Design and Analysis Application. Coll. of Agric., Univ. of Baghdad, Ministry of Higher Edu. and Scientific Res.

12. Fleming, T. 2000. PDR for Herbal Medicine. Medical Economics Co. Inc. Montvale, USA. p. 395-396.

13. Harten, A. M.; C. J. J. M. Raemakers; E. Jacobsen and G. Y. P. Kiu. 2004. Direct organogenesis and somatic embryogenesis in mature cotyledon explant of winged bean (Psophocarpus tetagonoiobus L.) DCI using cytokinine-based media. Plant Genetic Resources. News Letter Issue. 131: 63-69.

14. Iqbal, M. J., N. Aziz; N. A. Saeed; Y. Zafar and K. A. Malik. 1997. Genetic diversity evaluation of some elite cotton varieties by RAPD analysis. Theor. Appl. Genet. 94: 139144.

15. Khan, N. A.; R. Nazar and N. A. Anjum. 2009. Growth. Photosynthesis and antioxidant metabolism in mustard (Brassica juncean L.) cultivars differing in ATP-Sulfurylase activity under Salinity stress. Sci. Hort. 122: 455-460.

16. Murashige, T. and F. Skoog. 1962. A revised medium for rapid growth and bioassay with tobacco tissue cultures. Physiol. Planta. 15: 473-497.

17. Mustafa, N. R.; W. Winter; F. Iren and R. Verpoorte. 2011. Initiation, growth and
والتي قد تعزى إلى تأثثر هذا التركيز إلى احتمال احداث

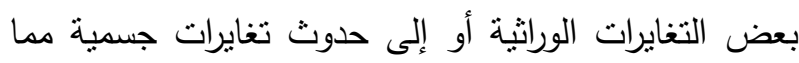
سبب حدوث تغير في تسلسل النيوكليوتيدات نتيجة الاضافة أو الحذف أو اعادة الترتيب للنيوكليوتيدات في ني نيلئيل معاملة التركيبين الوراثيين للجت بتراكيز مختلفة من ملح NaCl

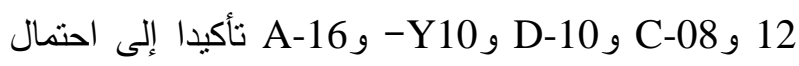
حدوث تغايرات وراثية في أنسجة الكالس المستحث من أجنة بذور الجت المزروع في وسط MS المجهز بالتركيز 300

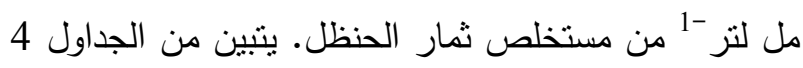

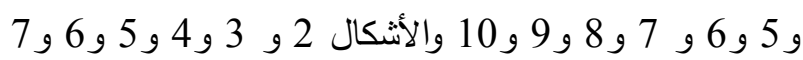

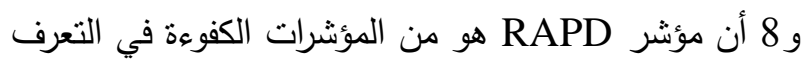
على التباين الوراثي بين الأنواع والأصناف النين النباتية

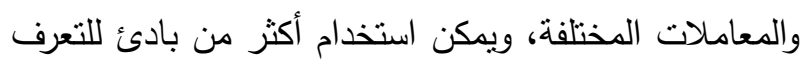

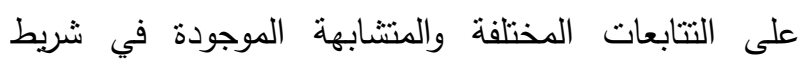

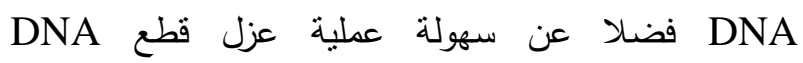
اعتمادا على الوزن الجزيئي، وهذه جاءت مؤكدة

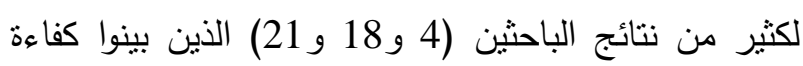
ثقانة RAPD-PCR في التعرف على التغايرات الوراثية.

\section{REFERENCES}

1. Al-Sahaf, F. H. 1989. Plant Nutrition Application. Dar Al-Kutob Publ., Mosul Univ. Ministry of Higher Edu., and Scientific Res, Iraq.

2. Al-Zubaidi, K. M. R. 2002. Effect of some Plant Extracts on Behavior Stored of Potatoes Var. Dazari. M.Sc. Thesis, Coll. of Agric., Univ. of Baghdad.

3. Baday, S. J. S. 2014. Role of some Phytohormones and Colocynth Fruits Extract in Vegetative Multiplication and Drought Tolerance of Sugarcane invitro. M.Sc. Thesis, Coll. of Agric., Univ. of Baghdad. pp. 113.

4. Balkrishna, R. A. and S. S. Shankarrao. 2013. In vitro screening and molecular genetic markers associated with salt tolerance in maize. Afric. J. Biol. 12(27): 4251-4255.

5. Barnes, D. and C. Sheaffer. 1995. Alfalfa. In R. Baarnes, D. Miller and C. Nelson (edrs.) - An Introduction to Grassland Agriculture . Iowa state Univ. Press. p. 205-216.

6. Brar, D. S. and S. M. Jian. 1998. Somaclonal variation: Mechanism and applications in crop improvement. In: S. M. 
cryopreservation of plant cell suspension cultures. Nat Prot. 6: 715-742.

18. Nevena, N.; T. Ksenija; B. Goran; B. Aleksandar; S. Ivana; D. Milic and S. Katic. 2011. Estimation of genetic diversity in tetraploid alfalfa populations based on RAPD markers for breeding purposes. Int. J. Mol. Sci. 12: 5449-5460.

19. Perez-Tornero, O.; C. L. Tallon; I. Porras and J. M. Navarro. 2009. Physiological and growth changes in micro-propagated Citrus macrophylla explants due to salinity. J. Plant Physiol. 166(17): 1923-1933.

20. Sambrook, J.; E. F. Fritsch and T. Maniatis. 1989. Molecular Cloning Alaboratory Manual. $2^{\text {nd }}$ Edn. Cold Spring Harbor, NewYork.

21. Sarid Ullah, S. M.; M. A. Hossain; M. M.Hossain; S. Barman; M. M. H. Sohag and S. H. Prodhan. 2013. Genetic diversity analysis of chewing sugarcane (Saccharum officinarum L.) varieties by using RAPD markers. J. Bio. Sci. Biotech. 2(2): 145-150.

22. Serrat, X.; R. Esteban; N. Guibourt; L. Moysset; S. Nogués and E. Lalanne. 2014. EMS Mutagenesis in Mature Seed-Derived Rice Calli as a New Method for Rapidly
Obtaining TILLING Mutant Populations. Plant Methods. p. 3-13.

23. Shukri, W. M. and R. M. Al-Meaqel. 2013. Plant Cell and Tissue Culture. Al-Mutanabi Lab., Al-Damam, KSA.

24. Syeed, S.; N. A. Anjum; R. Nazar; N. Iqbal; A. Masood and N. A. Khan. 2010. Salicylic acid-mediated Changes in photosynthesis, nutrients content and antioxidant metabolism in two mustard (Brassica juncean L.) cultivars differing in Salt tolerance. Acta. Plant Physiol: 10: 11-17. 25. Touil, L.; F. Guesimi; K. Fares; C. Zagrouba and A. Ferchichi. 2008. Genetic diversity of some Mediterranean populations of the cultivated alfalfa (Medicago sativa L.). J. Sci. 11(15): 1923-1928.

26. Williams, K. J.; A. Kubelik; K. Livak; J. Rafalski and S. Tingey. 1990. DNA polymorphic amplified by arbitrary primers are useful as genetic markers. Nucleic Acids Res. 18: 6531-6535.

27. Zaid, A.; H. G. Hughes; E. Porceddu and F. W. Nicolas. 1999. Glossary of Biotechnology and Genetic Engineering. FAO Res. Tech. Food and Agric. Org. of the United Nations. Rome, Italy. 